CUPAUAM 21, 1994, pp. 117-158

\title{
ICONOGRAFÍA DIONISÍACA EN LUCERNAS DE LA HISPANIA ROMANA
}

\author{
DARÍO BERNAL CASASOLA \\ Universidad Autónoma de Madrid \\ OSCAR GARCÍA SANZ \\ C.S.I.C.
}

\section{Resumen}

Este trabajo tiene como principal objetivo la sistematización de las escenas de tipo dionisíaco documentadas en lucernas aparecidas en Hispania. Se adjunta un repertorio de los motivos siguiendo un criterio temático (Baco, sátiros-silenos, ménades, panteras, máscaras...), realizando a continuación un estudio iconográfico de cada una de las representaciones documentadas. Se integran estos datos con los aportados por el estudio estrictamente arqueológico de las lucernas documentadas ( 88 piezas en total), extrayendo puntualizaciones cronológicas de interés.

\section{Summary}

This research tries to gather the bachic-type scenes decorating lamps found in ancient forman Spain. After making a list of the motifs recognized according to a thematic subject, a summarized iconographical analysis of each one of them is carried out. Joining these data with the ones from the archaeological study of the lamps, we also offer some cronological intervals of frequency in each case.

\section{INTRODUCCIÓN}

El objeto de este trabajo es dar a conocer el conjunto de lucernas de época romana aparecidas en la Península Ibérica que presentan decoración con motivos del ámbito dionisíaco. Nuestro propósito es en primer lugar agrupar todas las piezas que de modo disperso hemos podido encontrar en la bibliografía al uso. De igual modo, hemos tratado de configurar uną tipología iconográfica, reuniendo en ella todos los motivos conocidos por nosotros hasta la fecha. Nos hemos limitado a consultar aquellas obras que, de manera 
específica, tratan con materiales de estas características. No obstante, conscientes de las ausencias que puedan ser detectadas debido a la elevada frecuencia de aparición de este tipo de elementos de Cultura Material en intervenciones arqueológicas de toda índole, creemos que el conjunto de piezas aquí recogidas constituye una muestra lo suficientemente significativa para proceder a la elaboración de un análisis iconográfico, el cual no será, en nuestra opinión, alterado en gran medida por posteriores hallazgos.

Dado el interés de la clasificación iconográfica que Bailey aplicó al elaborar el estudio de los materiales del British Museum, y la utilidad de la misma para la consulta específica de un motivo en particular, nos ha parecido oportuno elaborar una clasificación similar, adaptada a las piezas de nuestro entorno geográfico (Bailey 1980; 1988). El enfoque que nosotros planteamos es la elección prioritaria de un tema iconográfico, el mundo báquico en nuestro caso, procediendo a reunir todas las posibles variantes decorativas que en tomo a dicho tema se han ido desarrollando. Normalmente, el análisis iconográfico vinculado al estudio de materiales arqueológicos en el ámbito de las Artes Industriales se limita a catalogar de manera correlativa todos los paralelos posibles, primero en el mundo de dicha producción (Terra Sigillata, lucernas, vidrio...) y en segundo término en otros campos artísticos afines. Nosotros, sin embargo, hemos querido partir de un criterio temático. A la hora de plantearnos la tarea de sistematizar todas las variantes iconográficas del mundo báquico, comenzamos rastreando en la bibliografía todas aquellas representaciones que estaban vinculadas a este entorno temático. Una vez realizada la selección y en función del material reunido, decidimos agrupar las piezas en tres grandes apartados: a) Baco, b) su cortejo (Sátiros y Ménades) y c) elementos relacionados con dicha divinidad. La existencia de variantes alternativas en cada grupo nos indujo a una división ulterior más compartimentada.

Una cuestión cuya aclaración se planteaba como imprescindible era la atribución báquica o no de determinados motivos no figurados cuando estos aparecían de manera aislada. Hemos tenido en consideración exclusivamente aquellos elementos que, vinculados unos a otros, ratificaban de manera evidente su conexión o simbología báquica. Tal es el caso de la frecuente representación de la crátera (Figura 1A). Este tipo de recipiente no es propiamente báquico en sí mismo, pero cuando acompaña a otros tales como tirsos, panteras, racimos,... sí es directamente vinculable a lo dionisíaco. Por tanto, sólo hemos incluido en nuestro análisis aquellos atributos que de manera encadenada no ofrecían duda alguna sobre su simbología. Renunciamos por tanto a considerar como báquicas aquellas representaciones aisladas de:

- Cráteras (Figura 1Aa).

- Cráteras con pámpanos (Figura 1Ab).

- Racimos y hojas de vid (Figura 1B).

- Amorcillos con uvas (Figura 1C) ${ }^{1}$.

1 Tanto la descripción del motivo del que hemos recogido la ilustración como el dibujo de la lucerna no son correctos, ya que Palanqués $(1992,66)$ no identifica los racimos de uvas que sostiene uno de los amorcillos. Estos racimos pueden verse claramente en la fotografía de la pieza recogida en su misma publicación (1992.377.lam.XXXIX.n." 1095), asi como en otras obras (Moreno 1991,1.552, mot. 261; Bernal 1993b, n." 184). 
Otras causas de exclusión han sido, bien la escasa definición del aparato gráfico aportado por los autores - hecho que no nos ha permitido en muchos casos corroborar la veracidad de la interpretación iconográfica por ellos realizada-, bien la particularidad del motivo en sí, que se ha traducido en la carencia de paralelos conocidos por nuestra parte.

Dentro del primer apartado se encuentran un posible "Baco sobre pantera" (Moreno 1991, 492, mot.167), un "Sátiro y ménade sobre asno" (1991, 536, mot.232), un "cortejo de Baco" (Fernández Chicarro 1952-53, n. ${ }^{\circ}$ 286) y unas "máscaras báquicas con copa báquica" (Mélida 1925, 1312). En el supuesto de la escasa veracidad de la identificación del motivo, tenemos documentada una pieza en la que se reconoce un motivo fragmentario como "sileno sobre asno" (Moreno 1991, 472, mot. 143) ${ }^{2}$, así como un supuesto ffauno joven" (1991, 681, n. $\left.{ }^{\circ} 609\right)$, un "fauno con flor" $\left(1991,682, \mathrm{n}^{\circ} 2702\right)$, otro efauno sin pelo" (1991, 682, n. $\left.{ }^{\circ} 3044\right)$, y un "sátiro con boca abierta" (1991, 474, mot. 146).

Tampoco hemos hallado paralelos del motivo identificado como "dos faunos tirando de una cuerda o toreando con una capa" (Fernández Chicarro 1952-3, 147, fig.51,14). Algunos autores (Fernández Chicarro 1952-3, n. ${ }^{\circ} 285$; Gil Farrés 1947-48, n. ${ }^{\circ} 57$ ) hablan de un "Baco/Sileno sobre asno" que nosotros no hemos podido documentar en el repertorio iconográfico consultado, ni tampoco el "Baco/Sileno a caballo" (Moreno 1991, n. ${ }^{\circ}$ 2961), del cual la propia autora se cuestiona la existencia de representaciones similares. Renunciamos asimismo, por motivos similares, a considerar la "cabeza de Baco barbudo de frente publicada por Palol (1948-9, 247, n. ${ }^{\circ} 32$, fig.104). Tras este proceso de selección, hemos establecido un índice de motivos que presentamos a continuación ${ }^{3}$ (Tabla 1). Hemos procedido a la ordenación de los motivos siguiendo un orden numérico de manera que el elenco pueda ser ampliado progresivamente cuando la documentación de representaciones no recogidas aquí induzca a ello.

Evidentemente, quedan fuera de esta taxonomía toda una serie de motivos de la esfera dionisíaca documentados en lucernas romanas procedentes de otras provincias del Imperio. Para facilitar la identificación iconográfica remitimos a estos efectos a las figuras 8 y 9 , en las que reproducimos dichos motivos no documentados por el momento en lucernas hispanas. Estas ilustraciones que hemos recogido han sido tomadas en su totalidad del repertorio de Bailey, ya que constituye hoy en día la clasificación temática mas completa. Así pues, en la figura 8 aparecen, siguiendo la división decimal de nuestra clasificación, todas las variantes iconográficas de los motivos recogidos por nosotros en Hispania. En la figura 9 reunimos aquellos motivos que no figuran en nuestra clasificación ${ }^{4}$.

2 A pesar de haber incluido esta representación en nuestro índice de motivos (n. ${ }^{\circ} 2.9$ ), ésta pieza concreta no la consideramos como tal en el Catálogo dada la fragmentariedad de la misma.

3 Acerca de la nomenclatura adoptada en el indice de motivos, hemos tenido en cuenta la terminología propuesta por Bádenas y Olmos (1988) para las alusiones a recipientes cerámicos, y la de Grinó (1985. 151-167) para los instrumentos musicales.

4 Las piezas Q 753-1483 corresponden al primer volumen de la colección de lucernas del Museo Británico (Bailey 1980), y las Q 1484-3522 al Il (Bailey 1988). 


\section{ÍNDICE DE MOTIVOS}

1. BACO.

1.1. Bustos.

1.1.1. Busto de Baco.

1.1.2. Busto de Baco con cuernos y palmeta.

1.1.3. Busto de Baco delante de pantera.

1.1.4. Bustos de Baco de perfil afrontados.

1.2. Baco sobre asno*.

1.3. Tigerreiter.

1.4. Baco apoyado sobre pantera.

1.5. Baco sentado con tirso.

1.6. Baco y Ariadna.

\section{SÁTIRO (s)/ SILENO (s).}

2.1. Bustos.

2.1.1. Busto de sátiro.

2.1.2. Busto de sileno.

2.2. Sátiro ebrio con cántaros.

2.3. Sátiro danzante (motivo fragmentario)*

2.4. Sileno danzante con timiaterio.

2.5. Sátiro danzante con tirso y nébrida.

2.6. Sátiro yacente sobre odre.

2.7. Sátiro moliendo.

2.8. Sátiro itífalo con ménade tocando el tympanon*

2.9. Sileno sobre asno.

\section{MÉNADE (s).}

3.1. Ménade danzante (motivo fragmentario)*.

3.2. Ménade danzante con tirso tocando los crótalos.

3.3. Ménade danzante con tirso ante altar.

3.4. Ménade danzante tocando el tympanon.

3.5. Ménade danzante con tirso tocando la siringa.

3.6. Ménade danzante con tirso y tympanon.

3.7. Ménade danzante con cuchillo y cabrito.

4. PANTERA (s).

4.1. Pantera sobre crátera con racimos de uva.

4.2. Dos panteras afrontadas y crátera.

4.3. Pantera y crátera.

5. MÁSCARA (s).

5.1. Máscara frontal exenta.

5.2. Mácara lateral con soporte.

6. ELEMENTOS BÁQUICOS ASOCIADOS: pantera con elementos báquicos diversos.

Tabla 1. Índice de motivos, con la numeración de las representaciones citadas en el texto. (* De estos cuatro motivos no ofrecemos ilustración en las tablas 2-5, dado el estado fragmentario de las piezas en un caso y la deficiente calidad de la representación aportada por los diversos autores en las otras.) 


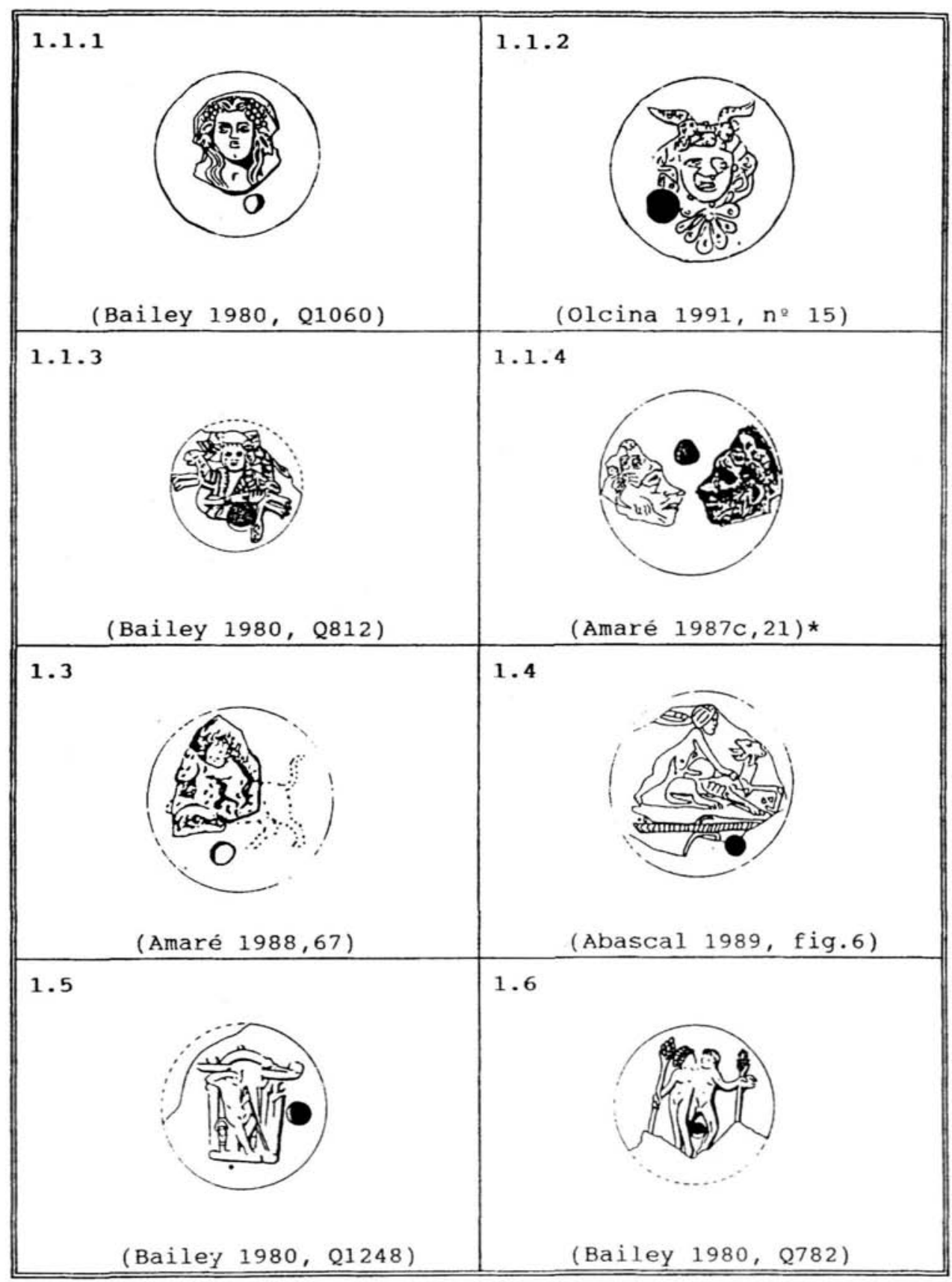

Tabla 2. Índice de Motivos (1). Representaciones de Baco 


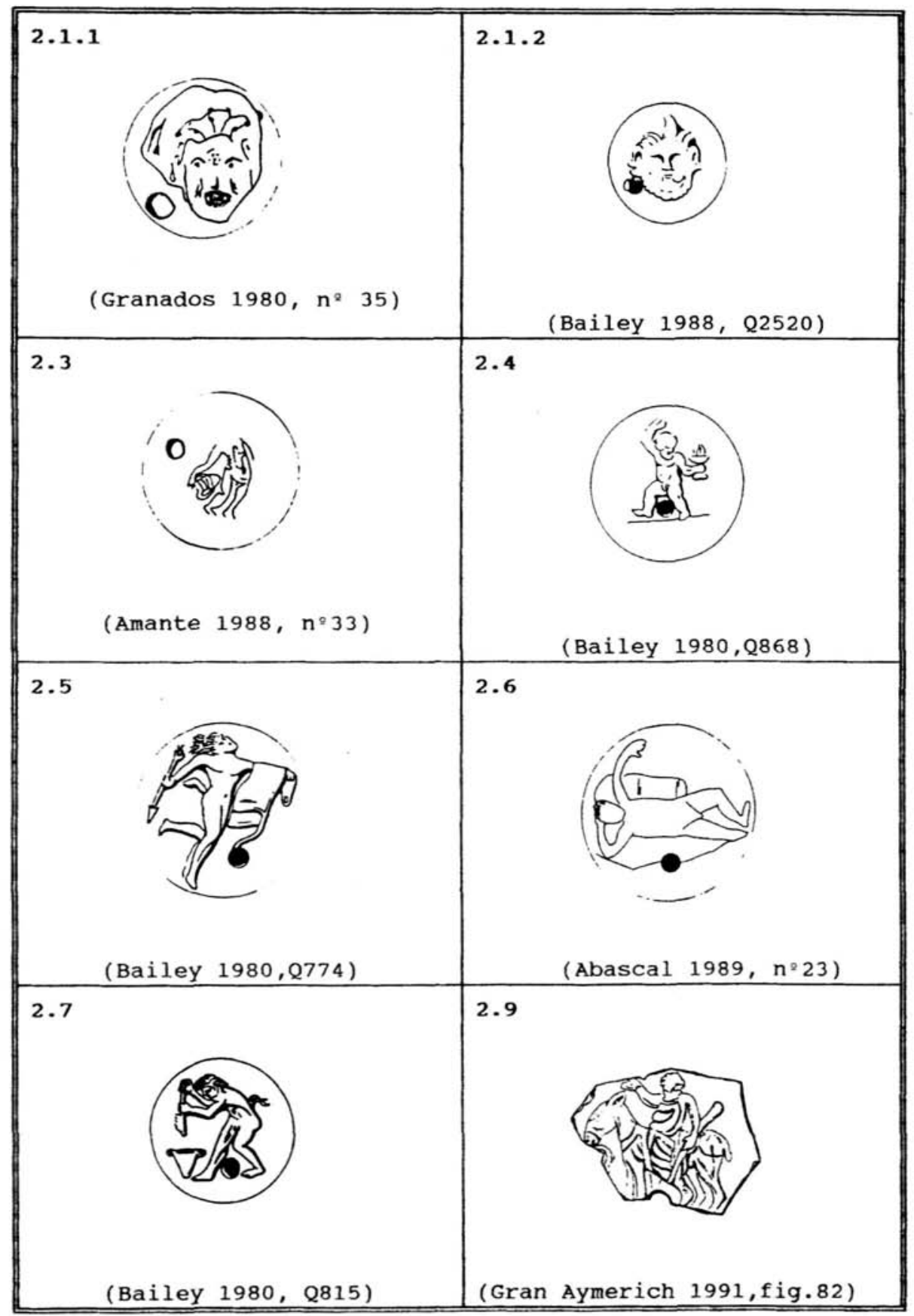

Tabla 3. Índice de Motivos (II). Representaciones de sátiros/silenos 


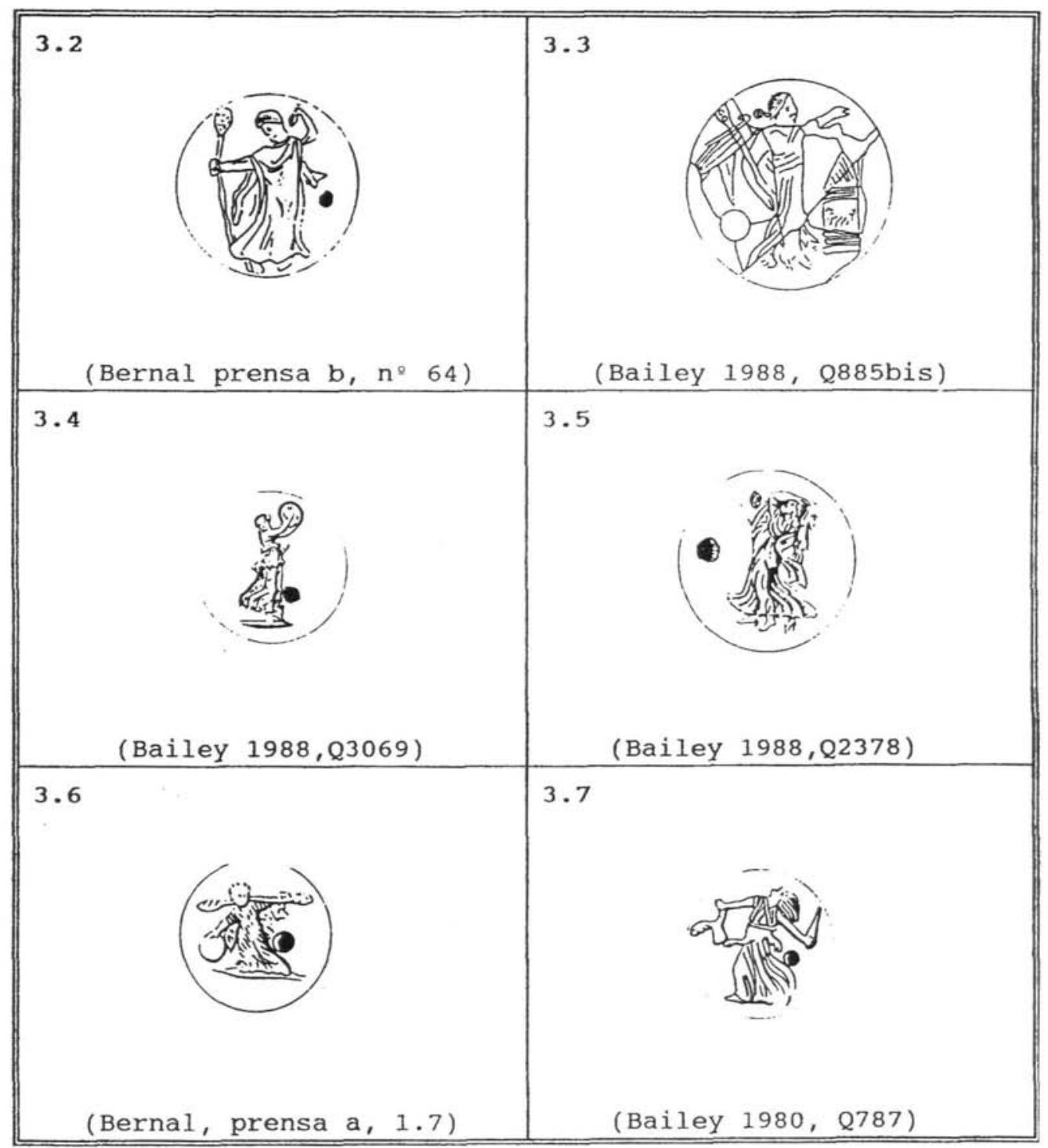

Tabla 4. Índice de Motivos (III). Representaciones de ménades

Dado el carácter monográfico de las obras que tratan de las lucernas que aquí tenemos en consideración, hemos prescindido de una descripción exhaustiva de cada una de ellas. Remitimos a tales efectos al apartado de bibliografía de nuestro Catálogo de Referencia. 


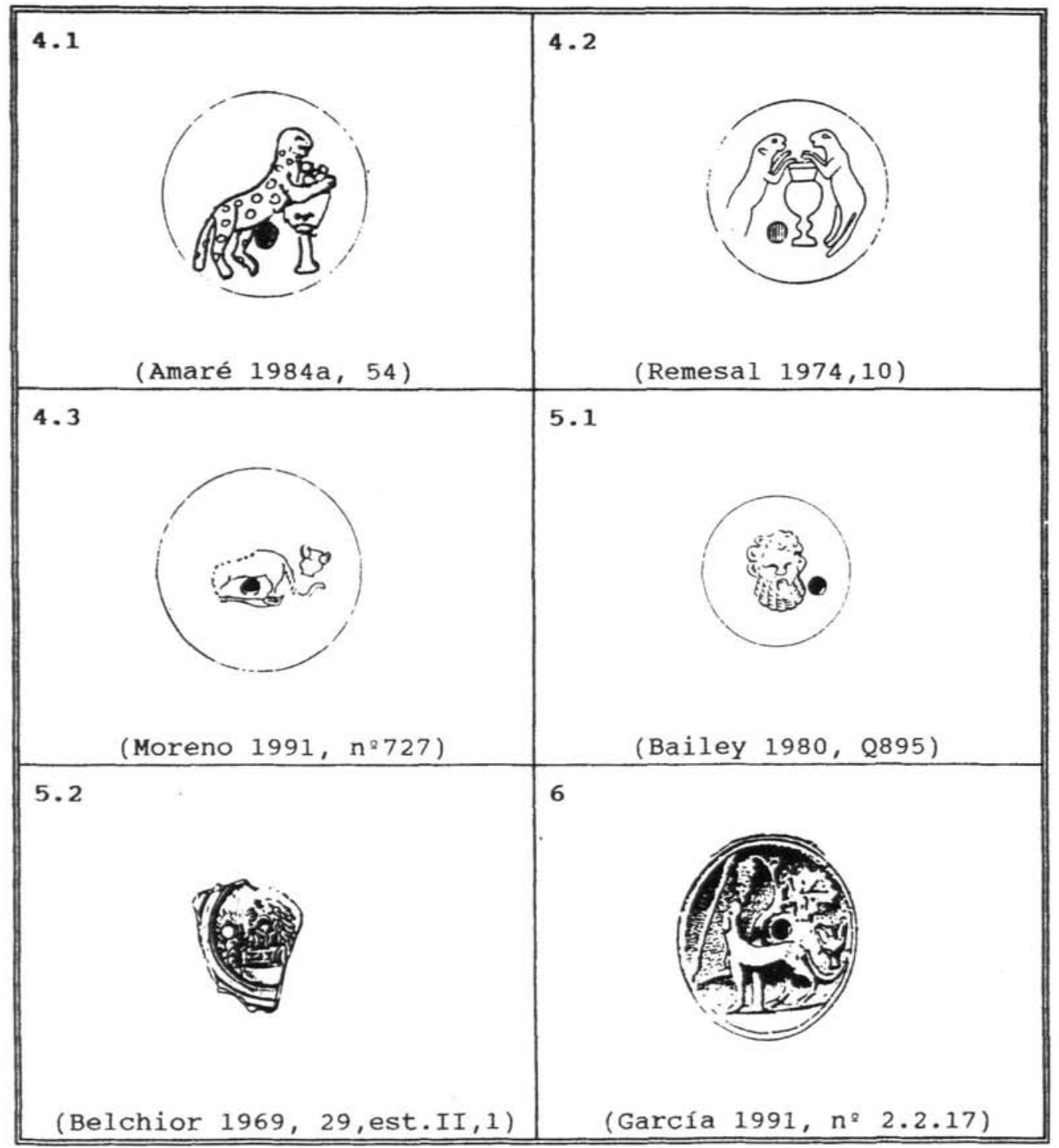

Tabla 5. Índice de Motivos (IV). Representaciones de máscaras y elementos báquicos asociados 
Los datos fundamentales que sí hemos tenido en cuenta son (Tabla 6):

\begin{tabular}{|c|c|c|c|c|c|}
\hline N. ${ }^{\circ}$ CAT. & MOTIVo & TIPO & CRONO. & PROCED. & BIBLIOGRAFÍA \\
\hline 01 & 1.1 .1 & ind. & altoimp. & Mérida & García. 1991, n. ${ }^{\circ} 2.2 .1$ \\
\hline 02 & 1.1 .1 & D. $\mathrm{Xb}$ & ss. II-III & Mérida & García. 1991, n. ${ }^{\circ} 2.1 .20$ \\
\hline 03 & 1.1 .2 & ind. & altoimp. & Tossal Manises & Olcina, 1991, n. ${ }^{\circ} 15$ \\
\hline 04 & 1.1 .2 & D. 11 & S. I & Cádiz & Moreno, 1991, n. 479 \\
\hline 05 & 1.1 .3 & ind. & altoimp. & Tossal Manises & Olcina, $1991, n .^{\circ} 38$ \\
\hline 06 & 1.1 .3 & D. $9 \mathrm{~B}$ & s. I & Osuna & Rde. Neila, 1977, n. ${ }^{\circ} 8$ \\
\hline 07 & 1.1 .3 & ind. & altoimp. & Conimbriga & Belchior, 1968, n. $^{\circ} 77$ \\
\hline 08 & 1.1 .3 & ind. & altoimp. & Indeterminada & Ferreira, 1953, n. $^{\circ} 18$ \\
\hline 09 & 1.1 .4 & ind. & altoimp. & Alcalá Henares & Amaré, $1987 \mathrm{c}, \mathrm{n}^{\circ} 21$ \\
\hline 10 & 1.2 & ind. & altoimp. & Mérida & García. 1991, n. ${ }^{\circ} 2.2 .2$ \\
\hline 11 & 1.2 & D. 11 & s. I & Cerro Muriano & Moreno, 1991, n. $^{\circ} 621$ \\
\hline 12 & 1.3 & ind. & altoimp. & Calatayud & Amaré, 1988, n. 67 \\
\hline 13 & 1.3 & vol & s. I & Tarragona & Bernal, 1993b, n. 93 \\
\hline 14 & 1.4 & ind. & altoimp. & Tossal Manises & Olcina, 1991, n. $^{\circ} 40$ \\
\hline 15 & 1.4 & ind. & altoimp. & Segóbriga & Abascal, 1989, n. $^{\circ} 60$ \\
\hline 16 & 1.5 & ind. & altoimp. & Calahorra & Amaré, 1978a, n. ${ }^{\circ} 43$ \\
\hline 17 & 1.6 & ind. & altoimp. & Córdoba & García. 1991, n. ${ }^{\circ} 2.2 .3$ \\
\hline 18 & 2.1 .1 & ind. & altoimp. & V. Barros & García. 1991, n. ${ }^{\circ} 2.2 .4$ \\
\hline 19 & 2.1 .1 & ind. & altoimp. & C. Santisteban & García. 1991, n. ${ }^{\circ} 2.2 .5$ \\
\hline 20 & 2.1 .1 & ind. & altoimp. & Mérida & García. 1991, n. ${ }^{\circ} 2.2 .9$ \\
\hline 21 & 2.1 .1 & D. 20 & $50-150$ & Barcelona & Granados, 1980, n. 35 \\
\hline 22 & 2.1 .1 & D. 15 & $50-150$ & Itálica & Fdez. Chic., 1952-53, n. ${ }^{\circ} 283$ \\
\hline 23 & 2.1 .1 & ind. & altoimp. & S. de Daró & Nolla, 1984, n. ${ }^{\circ} 146$ \\
\hline 24 & 2.1 .1 & vol. & S. I & Badajoz & Moreno, 1991, n.' 2.288 \\
\hline 25 & 2.1 .2 & D. $9 \mathrm{C}$ & S. I & Ampurias & Palol, 1948-49, n. 32 \\
\hline 26 & 2.1 .2 & D. 24 & S. II & Museo Sevilla & Fdez. Chic., 1952-53, n. ${ }^{\circ} 140$ \\
\hline 27 & 2.2 & ind. & altoimp. & Cartagena & Amante, 1988, n. $^{\circ} 33$ \\
\hline 28 & 2.3 & ind. & altoimp. & Ampurias & Palol, 1948-49, n. ${ }^{\circ} 113$ \\
\hline 29 & 2.3 & ind. & altoimp. & Ampurias & Palol, 1948-49, n. ${ }^{\circ} 114$ \\
\hline 30 & 2.3 & ind. & altoimp. & Ampurias & Palol, 1948-49, n. ${ }^{\circ} 115$ \\
\hline 31 & 2.3 & ind. & altoimp. & Ampurias & Palol, 1948-49, n. ${ }^{\circ} 116$ \\
\hline 32 & 2.3 & ind. & altoimp. & Ampurias & Palol, 1948-49, n. ${ }^{\circ} 117$ \\
\hline 33 & 2.3 & ind. & altoimp. & Ampurias & Palol, $1948-49$, n. $^{\circ} 118$ \\
\hline 34 & 2.3 & ind. & altoimp. & Mérida & García, 1991, n. ${ }^{\circ} 2.2 .11$ \\
\hline 35 & 2.3 & ind. & altoimp. & Córdoba & Moreno, 1991, n. $^{\circ} 980$ \\
\hline 36 & 2.5 & D. $9 \mathrm{~A}$ & S. I & Córdoba & Rdez. Neila, $1978-79$, n. $^{\circ} 7$ \\
\hline 37 & 2.5 & D. 20 & $50-150$ & Museo Sevilla & Fdez. Chic., 1952-53, n. ${ }^{\circ} 130$ \\
\hline 38 & 2.5 & ind. & altoimp. & Mérida & García, 1991, n. ${ }^{\circ} 2.2 .10$ \\
\hline 39 & 2.6 & ind. & altoimp. & Segóbriga & Abascal, $1989, \mathrm{n}^{\circ} 23$ \\
\hline
\end{tabular}


(Continuación Tabla 6):

\begin{tabular}{|c|c|c|c|c|c|}
\hline N. ${ }^{\circ}$ CAT. & MOTIVO & TIPO & CRONO. & PROCED. & BIBLIOGRAFÍA \\
\hline 40 & 2.6 & D. 11 & s. I & Baleares & Domergue, 1966, n. $^{\circ} 26$ \\
\hline 41 & 2.6 & D. 11 & S. I & Baleares & Domergue, 1966, n. $^{\circ} 26$ \\
\hline 42 & 2.6 & D. 11 & S. I & Baleares & Domergue, 1966, n. $^{\circ} 26$ \\
\hline 43 & 2.6 & ind. & altoimp. & Itálica & Fdez. Chic., 1952-53, n. ${ }^{\circ} 300$ \\
\hline 44 & 2.7 & ind. & altoimp. & Segóbriga & Abascal, $1989, n^{\circ} 39$ \\
\hline 45 & 2.7 & ind. & altoimp. & Segóbriga & Abascal, 1989, n. $^{\circ} 47$ \\
\hline 46 & 2.8 & D. 11 & S. I & Porcuna & Moreno, 1991, n. $^{\circ} 1.814$ \\
\hline 47 & 2.9 & ind. & altoimp. & Málaga & Gran Aym., 1991, fig. 300, 1 \\
\hline 48 & 3.1 & ind. & altoimp. & Indeterminada & García, 1991, n. ${ }^{\circ} 2.2 .13$ \\
\hline 49 & 3.1 & ind. & altoimp. & Ampurias & Palol, 1948-49, n. ${ }^{\circ} 121$ \\
\hline 50 & 3.2 & D. $9 \mathrm{~B}$ & S. I & Museo Tarragona & Bernal, 1993b, n. ${ }^{\circ} 64$ \\
\hline 51 & 3.2 & ind. & altoimp. & Tossal Manises & Olcina, 1991, n. $^{\circ} 41$ \\
\hline 52 & 3.2 & D. $9 \mathrm{~A}$ & S. I & Cerro Muriano & Álvarez, 1942, n. $^{\circ} 280$ \\
\hline 53 & 3.3 & D. 11 & S. I & Ceuta & Bernal, 1995, n. ${ }^{\circ} 1.7$ \\
\hline 54 & 3.4 & D. 20 & $50-150$ & Barcelona & Granados, 1980, n. $^{\circ} 27$ \\
\hline 55 & 3.4 & D. 20 & $50-150$ & Peroguarda & Moutinho, 1976,81, n. $^{\circ} 2$ \\
\hline 56 & 3.4 & ind. & altoimp. & Baelo & Remesal, 1974,562, n. $^{\circ} 7$ \\
\hline 57 & 3.5 & D. $9 \mathrm{~A}$ & s. I & Arcobriga & Amaré, 1988, n. ${ }^{\circ}$ 68, fig. 106 \\
\hline 58 & 3.6 & ind. & altoimp. & Calatayud & Amaré, 1988 , n. ${ }^{\circ} 68$, fig. 107 \\
\hline 59 & 3.6 & ind. & altoimp. & Ampurias & MMAprov, $1948-49$, n. $^{\circ} 120$ \\
\hline 60 & 3.7 & D. 11 & S. I & Cádiz & Moreno, 1991, n. 331 \\
\hline 61 & 3.7 & vol. & S. I & Calatayud & Amaré, 1988, n. $^{\circ} 68$, fig. 105 \\
\hline 62 & 3.7 & ind. & altoimp. & Segóbriga & Abascal, 1989, n. ${ }^{\circ} 49$ \\
\hline 63 & 3.7 & D. $9 \mathrm{~A}$ & S. I & S. de Daró & Nolla, 1984, n. $^{\circ} 146$ \\
\hline 64 & 3.7 & ind. & altoimp. & Ampurias & Palol, 1948-49, n. ${ }^{\circ} 121$ \\
\hline 65 & 3.7 & ind. & altoimp. & Ampurias & Palol, 1948-49, n. ${ }^{\circ} 122$ \\
\hline 66 & 4.1 & D. 15 & $50-100$ & Santiago Cacem & García, 1991, n. ${ }^{\circ} 2.2 .16$ \\
\hline 67 & 4.1 & ind. & altoimp. & Calatayud & Amaré, 1988, n. ${ }^{\circ} 68-69$ \\
\hline 68 & 4.1 & ind. & altoimp. & Calatayud & Amaré, 1988, n. ${ }^{\circ} 68-69$ \\
\hline 69 & 4.1 & D. 11 & S. I & Tugi & Moreno, 1991, n. ${ }^{\circ} 1.811$ \\
\hline 70 & 4.1 & D. 11 & s. I & Córdoba & Rgez. Neila, 1978-79, n. ${ }^{\circ} 30$ \\
\hline 71 & 4.1 & D. 12 & S. I & Osuna & Moreno, 1991, n. 3.148 \\
\hline 72 & 4.1 & ind. & altoimp. & Zuheros & Moreno, 1991, n. ${ }^{\circ} 1.816$ \\
\hline 73 & 4.1 & ind. & altoimp. & Mérida & Gil, 1947-48, n. ${ }^{\circ} 64$ \\
\hline 74 & 4.2 & Dis. & ss II-III & Bolonia & Remesal, 1974, n. ${ }^{\circ} 562$ \\
\hline 75 & 4.3 & ind. & altoimp. & Córdoba & Moreno, 1991, n. ${ }^{\circ} 727$ \\
\hline 76 & 5.1 & ind. & altoimp. & Itálica & García, 1991, n. ${ }^{\circ} 2.2 .6$ \\
\hline 77 & 5.1 & ind. & altoimp. & Mérida & Gil, 1947-48, n. ${ }^{\circ} 51$ \\
\hline 78 & 5.1 & ind. & altoimp. & Mérida & García, 1991, n. ${ }^{\circ} 2.2 .8$ \\
\hline
\end{tabular}




\begin{tabular}{|c|c|c|c|c|c|}
\hline N. ${ }^{\circ}$ CAT. & MOTIVO & TIPO & CRONO. & PROCED. & BIBLIOGRAFIA \\
\hline 79 & 5.1 & ind. & altoimp. & Arcóbriga & Amaré, 1988, n. $^{\circ} 69$ \\
\hline 80 & 5.1 & ind. & altoimp. & Segóbriga & Abascal, 1989, n. ${ }^{\circ} 52$ \\
\hline 81 & 5.1 & D. 11 & s. I & Mérida & Fdez. Chic., 1952-53, n. ${ }^{\circ} 72$ \\
\hline 82 & 5.1 & D. 11 & s. I & Badajoz & Moreno, 1991, n. $^{\circ} 2.722$ \\
\hline 84 & 5.1 & D. 11 & s. I & Badajoz & Moreno, 1991, n. $^{\circ} 2.264$ \\
\hline 85 & 5.1 & vol. & S. I & Málaga & Gran Aym., 1991, fig. 82, n. 3 \\
\hline 86 & 5.1 & ind. & altoimp. & Tarraco & Serra Vilaró, 1935, lám. 39 \\
\hline 87 & 5.2 & ind. & altoimp. & Conimbriga & Belchior, 1969, 29, est. II, 1 \\
\hline 88 & 6 & D. $9 \mathrm{~A}$ & s. I & Balsa & García, 1991, n. ${ }^{\circ} 2.2 .17$ \\
\hline
\end{tabular}

Tabla 6. Catálogo de Referencia

- N. ${ }^{\circ}$ Catálogo: es el número correlativo que hemos asignado a cada ejemplar, siguiendo un orden en función de la clasificación de motivos ya mencionada. A la hora de referirnos a cada una de estas piezas, hacemos referencia exclusiva a este dígito, con el objeto de poder distinguir entre varias lucernas decoradas con este mismo motivo.

- Motivo: es numeración coincide con la del índice de motivos.

- Tipo: en este apartado hacemos referencia a la tipología a la que adscribimos cada lucerna. Las abreviaturas que hemos utilizado son las siguientes: tario de la pieza.

- Ind.: de tipo indeterminado, en todos los casos debido al estado fragmen-

- Vol.: lucerna de volutas. Tampoco podemos especificar más la forma precisa, dada su fragmentariedad, pero sí la podemos incluir en esta familia por sus atributos morfológicos.

- Dis.: lámpara de disco. Ocurre como en el caso anterior. Podemos considerarla como perteneciente a los tipos de lucernas de disco por sus peculiaridades formales.

Las dos tablas tipológicas a las que hemos hecho referencia son:

- D.+...: alude a la clasificación de Dressel (1899), que es la que hemos utilizado fundamentalmente al ser la más antigua y difundida. Tras la abreviatura se elenca el lugar numérico de la clasificación, que se reduce a D.9A,9B,9C,11,12,15,20 y 24.

- D.+...: abreviatura de Deneauve (1969), que hace referencia a su tipología. Sólo tenemos una de las formas, la Deneauve $\mathrm{Xb}$. 
- Cronología: la cronología que aplicamos a cada pieza no coincide en todas las ocasiones con las aportadas por los diversos autores. Hemos, por tanto, procedido a actualizarlas, pues algunas obras, debido a su antigüedad, no han podido tener en cuenta las matizaciones de los últimos años. Sin embargo, dadas las características de nuestro estudio, tampoco hemos querido precisar mucho en este aspecto, circunscribiéndonos a intervalos temporales más o menos amplios. Tal es el caso de las D.9, para las cuales hemos optado por una datación del s. I, no habiendo recurrido a los contextos del limes para precisar más. Evidentemente, la datación se hace en función de la morfología, pues los datos aportados por los contextos arqueológicos de procedencia de las piezas son, en la mayor parte de los casos, mínimos.

- Altoimp.: nos indica una cronología altoimperial (s. I-II d.C) para la pieza. En la totalidad de los casos, esta atribución cronológica tan amplia se debe al estado fragmentario de las piezas, hecho que dificulta su adscripción tipológica. No obstante, es evidente que se ajustan a este intervalo cronológico, ya que todas estas piezas son de volutas o disco, en función de las proporciones del propio disco y de las características de la decoración, propia de los dos primeros siglos de nuestra Era.

- Procedencia: indica el lugar de procedencia de la pieza en cuestión. Hemos optado por el nombre actual de la localidad, pues al tratarse en no pocas ocasiones de colecciones museísticas, al hacer referencia al contexto de la aparición, se detalla exclusivamente el área administrativa más próxima (normalmente la provincia). En el caso en que hagamos alusión a un Museo (n. ${ }^{\circ} 26$ o n. ${ }^{\circ} 50$ ), se entiende que la pieza constituye un depósito de origen desconocido. A pesar de haber centrado nuestro estudio en la Hispania romana altoimperial, incluimos una pieza del s. I d.C. procedente de la actual ciudad de Ceuta. Si bien somos conscientes de que dicho enclave, como parte de la Mauritania Tingitana, no entra a formar parte de la Diocesis Hispaniarum hasta época de Diocleciano, tenemos en cuenta esta lucerna dada la singularidad del motivo representado.

- Bibliografia: se incluye en este apartado la referencia en la que se da noticia de la pieza. Debido a la pluralidad de referencias para una misma lucerna, hemos elegido una sola por motivos de falta de espacio en la disposición del Catálogo. Con el objeto de evitar confusiones, ofrecemos al final una tabla de equivalencias, allí donde se dan (Tabla 7).

\section{ANÁLISIS ICONOGRÁFICO Y TIPOLÓGICO}

Como comentario sucinto al Índice de motivos ilustrado en las Tablas 2-5, efectuamos a continuación una referencia a los prototipos iconográficos de las representaciones en los discos de las lucernas que hemos podido localizar en otros campos artísticos dentro del Mundo Clásico. Algunos motivos no poseen un paralelo evidente, sino que, bien son composiciones a base de otros motivos, bien solo pueden ser verificados en paralelos ornamentales en el campo de las lucernas, de los que no nos vamos a ocupar aquí. 
Para los paralelos en el mundo de las lucernas en todo el Mediterráneo remitimos a la cita bibliográfica de la que hemos extraido el motivo en cada contexto ( $c f r$. Tabla 6.- Catálogo de referencia). El tamaño reducido de la superficie decorable en cada pieza, que como sabemos se circunscribe al disco salvo en el caso de motivos de pequeñas dimensiones que también se distribuyen por las margines y el propio asa, determina en gran medida el desarrollo iconográfico. Este fenómeno puede comprobarse en algunas de nuestras piezas, ya que solamente cuatro de ellas presentan composiciones formadas por más de un motivo, pues éstos ocupan la totalidad de la superficie decorable del disco y no permiten una mayor profusión de elementos figurados. Asimismo esta limitación espacial es la que ha condicionado la ausencia de determinadas escenas tradicionalmente representadas en el mundo dionisíaco. Tal es el caso del "Triunfo de Baco en la India", compuesto por el carro, tigres y otros animales, y su cortejo de sátiros, ménades, príapos, Ariadna y motivos vegetales varios.

\begin{tabular}{|c|c|c|}
\hline \multicolumn{3}{|c|}{ EQUIVALENCIAS BIBLIOGRÁFICAS } \\
\hline N. ${ }^{\circ}$ CAT & BIBLIOGRAFIA & EQUIVALENCIA \\
\hline 01 & García, 1991, n. ${ }^{\circ} 2.2 .1$ & Mélida CMBadajoz 1, 1.281 \\
\hline 10 & García, 1991, n. ${ }^{\circ} 2.2 .2$ & Gil, 1947-48, n. 57 \\
\hline 12 & Amaré, 1988, n. $^{\circ} 67$ & Amaré, $1984 a, n .^{\circ} 27$ \\
\hline 17 & García, 1991, n. ${ }^{\circ} 2.2 .3$ & García y Bellido, 1970 \\
\hline 18 & García, 1991, n. ${ }^{\circ} 2.2 .4$ & Fdez. Chic., 1952-53, n. ${ }^{\circ} 47$ \\
\hline 19 & García, 1991, n. ${ }^{\circ} 2.2 .5$ & Mélida CMBadajoz 1, 1.309 \\
\hline 20 & García, 1991, n. 2.2 .9 & García, 1991, n. ${ }^{\circ} 2.2 .7$ \\
\hline 26 & Fdez. Chic., 1952-53, n. ${ }^{\circ} 140$ & Gil, $1947-48,114,1$ \\
\hline 34 & García, 1991, n. ${ }^{\circ} 2.2 .11$ & Mélida CMBadajoz 1, 1.310 \\
\hline 38 & García, 1991, n. ${ }^{\circ} 2.2 .10$ & López Rdgez., 1981, n. ${ }^{\circ} 166$ \\
\hline 48 & García, 1991, n. ${ }^{\circ} 2.2 .13$ & Amaré, $1984 \mathrm{a}, \mathrm{n}^{\circ} 28$ \\
\hline 58 & Amaré, 1991, n. ${ }^{\circ} 2.2 .16$ & Ferreira, 1951, n. $^{\circ} 125-130$ \\
\hline 66 & García, 1991, n. ${ }^{\circ} 2.2 .16$ & Amaré, $1984 a, n{ }^{\circ} 30$ \\
\hline 67 & Amaré, 1988, n. ${ }^{\circ} 68-69$ & Amaré, $1984 a$, n. $^{\circ} 29$ \\
\hline 68 & Amaré, 1988, n. $^{\circ} 68-69$ & Moreno, 1991, n. $^{\circ} 1.152$ \\
\hline 70 & Rdgez. Neila, 1978-79, n. 30 & Fdez. Chic., 1952-53, n. ${ }^{\circ} 283$ \\
\hline 76 & García, 1991, n. ${ }^{\circ} 2.2 .6$ & Fdez. Chic., 1952-53, n. ${ }^{\circ} 721$ \\
\hline 78 & García, 1991, n. ${ }^{\circ} 2.2 .8$ & Leite, 1913, fig. 112 \\
\hline 88 & García, 1991, n. ${ }^{\circ} 2.2 .17$ & Ferreira, 1953 , est. 31,17 \\
\hline
\end{tabular}

Tabla 7. Equivalencias bibliográficas de las piezas citadas en el Catálogo

En una primera observación se aprecia la reducción del mundo dionisíaco a sus personajes principales: Baco y las versiones masculinas y femeninas del thíasos. Queda excluida la figura de Pan cuando aparece en solitario (Figura 1D). Esta representación por separado de sátiros y ménades no es habitual en la iconografía clásica, pues normalmente aparecen vinculados bien entre sí o bien con otros motivos del ámbito báquico. 
Por lo que se refiere a los elementos que podemos vincular a esta divinidad, considerándolos por tanto atributos simbólicos, son algunas las premisas a tener en cuenta, como ya hemos señalado en la introducción. Incluimos exclusivamente aquellos motivos que vinculados unos a otros de manera encadenada, inducen, sin posibilidad de duda, a su adscripción al repertorio dionisíaco. En este contexto situamos nuestros motivos 4 y 6 , entre los cuales el tema de la pantera es porcentualmente el más representativo.

Por lo que se refiere a los Bustos de Baco, las cuatro variantes iconográficas que hemos establecido, encuentran en el Arte Clásico claros precedentes:

El 1.1.1 es el tipo de Diónysos apolíneo (Tabla 2), muy empleado en el Helenismo en objetos como patas de mesa, acróteras, ménsulas, apliques, colgantes, etc. Esta figuración puede reconocerse en las cabezas de algunas esculturas de Baco apolíneo, como las del tipo Borguese-Colonna (LIMC 1986a, 121a), Richelieu (122f) o Kopenhagen-Valentini (124b). En la Hispania Romana hay dos ejemplares de idéntica factura: una cabeza procedente de Cádiz y otra de Mértola (García 1991a, 4.2.1 y 4.2.2.).

La lucerna del British Museum (Bailey 1980, Q1060) que ejemplifica esta variante está en estado fragmentario, no permitiendo una precisión tipo-cronológica. Lo mismo sucede con nuestro ejemplar n. ${ }^{\circ} 01$ (Tabla 6). En todo caso, ambas piezas son reconducibles a la familia de las lámparas de volutas-disco y por ello datables en un contexto de los dos primeros siglos de la Era. La ofrecida por Bailey es de manufactura itálica, y la nuestra podemos pensar que también, dada la poca trascendencia de las producciones locales de este tipo de piezas hasta en momento en Hispania. Sin embargo, la pieza n. ${ }^{\circ}$ 02 es un ejemplar ciertamente puntual. Se trata de una lucerna de producción africana, caracterizada por el infundibulum que adquiere forma figurada, en nuestro caso una cabeza de Baco, y por el rostrum, de forma peculiar y diagnóstica en este tipo de piezas. Es una de las piezas que arroja, circunscribiéndonos al mundo de las lucernas, la cronología más tardía de este grupo, es decir, un s. II-III d.C., alejándose de la media general que, como veremos, se centra sobre todo en el s. I d.C.

El 1.1.3 en cambio constituye la representación de un Baco con los atributos del banquete (hojas, cintas, corimbos, flores... ) y la nébrida. El mismo dios se representa así en un medallón circular de un mosaico tardío de Antioquía (LIMC 1986a, 54). No obstante, no conocemos paralelo decorativo exacto alguno de este motivo, salvo en el caso de las lucernas. El felino que se asoma por la parte trasera parece ser un anadido del alfarero, evidenciando la difundida costumbre en las diversas officinae de crear sus propios motivos mediante la manipulación, mezcla y alteración de los punzones difundidos por todo el Imperio 5 . Es pues normal no encontrar paralelos exactos en otros campos artísticos.

Las lucernas que presentan ornamentación de estas características se adscriben a los tipos Loeschcke I, IV y V, todos ellos propios del s. I d.C., si bien podemos encontrar alguna perduración hasta época trajanea. Los paralelos iconográficos de este motivo están difundidos por todo el Mediterráneo, desde Germania hasta Chipre, pasando, evi-

5 Para el tema de la manipulación de los punzones, aplicado al caso de las lucernas de época romana. son interesantes al respecto las consideraciones aportadas por J.Bonnet (1989, 15-22). 
dentemente, por la península itálica (Bailey 1980, 14-15; 1988, Q 2448). En Hispania nuestras piezas se centran de nuevo en el s. I d.C, pues la única que hemos podido clasificar morfológicamente con precisión se corresponde con una Dressel 9B, que oscila de época tiberiana a Claudio, y la otra arroja una cronología altoimperial imprecisa (n. ${ }^{\circ} 05-08$ ).

Los rostros afrontados de nuestro tipo 1.1.4 están bien documentados, así como la contraposición de Sátiro/Diónisos, Sátiro/Sileno o Baco joven/Baco anciano. Esta disposición nos recuerda a la empleada en la numismática de Naxos desde el s. v a.C. (LIMC 1986a, 177) y en las múltiples hermas bifrontes de Baco con rasgos, como en este caso, de Liber Pater (el dios agrario del vino en el Lacio), como las que encontramos en Pollentia y Segóbriga (García 1991a, 3.2.8 y 3.2.9). Nuestra lucerna n. ${ }^{\circ} 09$, la única que presenta este motivo, procede del Cerro de S. Juan del Viso en Complutum y no aporta matizaciones cronológicas. El tema forma parte de una composición doble, tal y como se documenta en alguna pieza del Museo de Chipre, pero también aparece aisladamente (Amaré 1987b, 21). En ella pueden distinguirse los atributos típicos de la corona báquica, como son el laurel, las flores, los corimbos,etc.

Sin embargo, la representación "d'un tête d'adolescent de profil à droite, surmontée d'une couronne de lauriers" hallada en Conimbriga (Alarcao y otros 1976, 103, n. ${ }^{\circ} 78$, est. XXVII ), así como otras piezas de La Rioja y Pollentia (Figura 2A), no reunen a nuestro juicio elementos iconográficos suficientes que nos permitan considerarlas como báquicas, contrariamente a la atribución propuesta. Además, no es este el único motivo con cabeza laureada, ya que conocemos otras representaciones también laureadas (Figura 2B), y no por ello asimilables al entorno dionisíaco. La presencia exclusiva de laurel como elemento ornamental se relaciona con el praemium exhibido por personajes como símbolo de victoria (militar,deportiva,honorífica...).

Esto evidencia como los moldes/arquetipos se decoraban con punzones diversos que generaban composiciones de índole variadísima. Así pues, tenemos aquí un testimonio de cómo los figuli hispani trabajaban no sólo mediante sobremoldes, sino también utilizando punzones (bien fuesen originales o copiados) para decorar las piezas de primera generación ${ }^{6}$. Por otro lado, existe un tipo de representación de una cabeza de perfil laureada (o bien dos enfrentadas) que ha sido identificada recientemente como una cabeza de Sileno (Amaré 1987a, 44, fig. 5 ; Palanqués 1992, 59). Sin embargo, nosotros no la incluimos aquí ya que a nuestro juicio no se trata de un motivo báquico. La presencia aislada de una corona de laurel no permite identificar al personaje como perteneciente al mundo báquico, y por ello no la tomamos en consideración ${ }^{7}$.

6 Es interesante contrastar el caso del taller de Montans, que emitía sus propios productos, en realidad copias por sobremolde de productos de importación (Berges 1989, 25-31).

7 Se trata de un motivo muy frecuente, que encuentra paralelos difundidos por todo el imperio, en Hispania concretamente en Pollentia, Ampurias y Vareia (Amaré 1987a, 44). Ha sido considerado en otras ocasiones como posiblemente satírico (Sapelli 1979, 55, n. ${ }^{\circ}$ 93), pero sin argumentos de tipo iconográfico que permitan verificar tal aserción. 


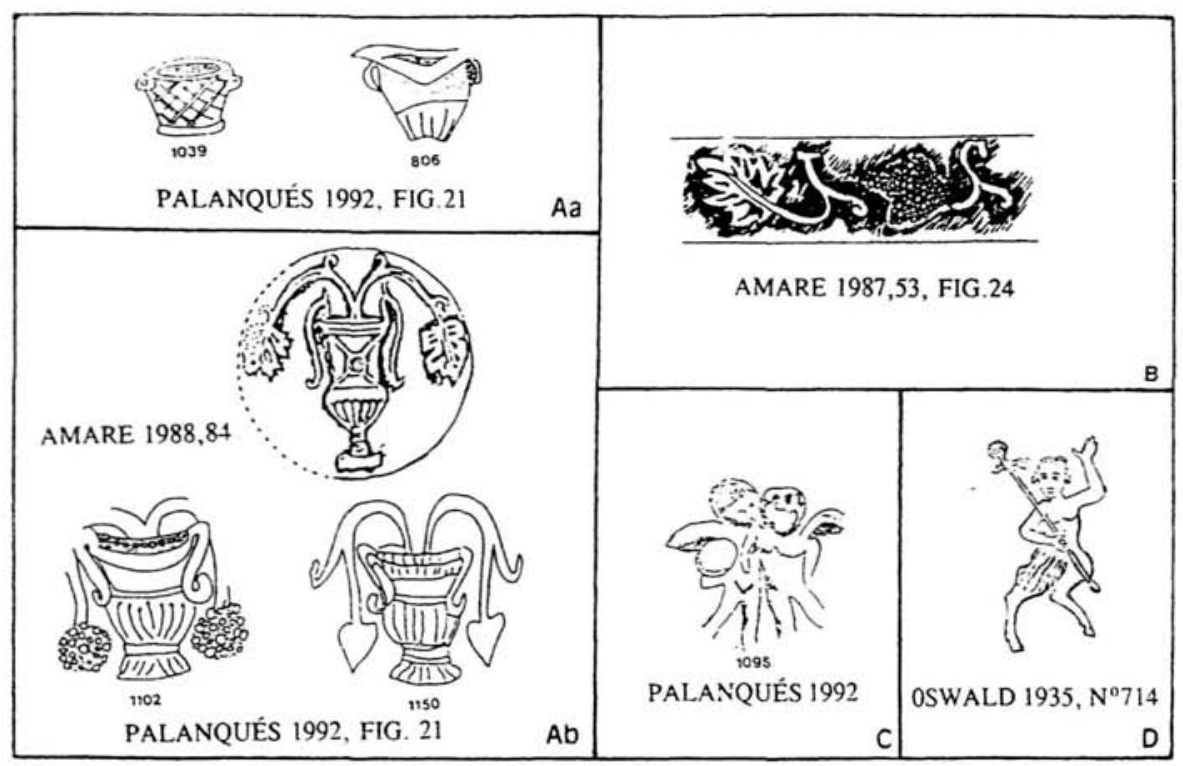

Figura 1. Representaciones de cráteras (Aa), cráteras con pámpanos (Ab), racimos y hojas de vid (B), amorcillos (C) y Pan (D)

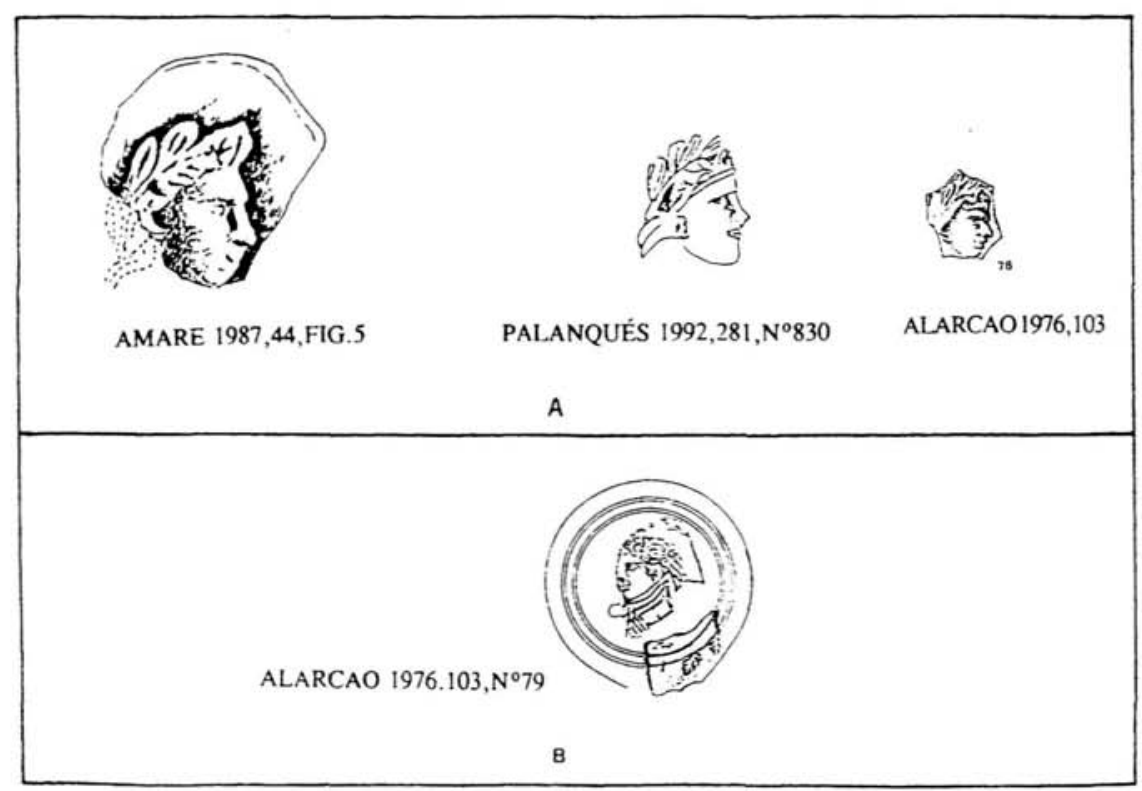

Figura 2. Representaciones de cahezas laureadas 
Por último la iconografía de 1.1.2 nos resulta problemática dados los siguientes cruces iconográficos: la presencia de corimbos y hojas de hiedra báquicos, los cuernos que nos recuerdan al dios tracio Zagreo, y la disposición de la palmeta y el conjunto como asimilable a las Gorgonas. Tras lo cual podemos proponer para este tipo la denominación de Gorgoneion báquico. Bailey lo incluye dentro del apartado "Dionysos and his followers", sin hacer ningún tipo de aclaración, pues sólo se cuestiona la dificultad de distinguir en este tipo de representaciones si se trata de Dionysos o de sátiros (1988, 8). Este autor cita paralelos en Colchester, Mencetter, Caerleon, Vindonissa, Trier, Brumath y varias en contextos suizos, todas del tipo Loeschcke IB (= Dressel 9B), y por tanto sincrónicas a las que ya tenemos $(1988,10)$. Nuestras dos piezas hispanas se insertan en este mismo contexto cronológico ( $n .^{\circ}$ 03-04).

El tipo 1.2 - Baco sobre asno- no es muy frecuente, y así lo demuestran las únicas dos piezas que hemos encontrado $\left(n .^{\circ} 10-11\right)$, que debemos tomar con cautela, pues el deficiente aparato gráfico aportado por los autores no nos ha permitido precisar mucho al respecto. Sí conocemos algún tipo de representación similar en lucernas ligadas al mundo báquico, como el caso de una pieza del British Museum en la que aparece un Sileno sobre un asno, y de la que el autor cita un paralelo en Colonia en el que el Sileno sostiene un ritón en la mano derecha (Bailey 1980, Q772), si bien este tema no es muy común en el mundo dionisíaco.

El ya consagrado tipo Tigerreiter o jinete del tigre de nuestro apartado $\mathbf{1 . 3}$ aparece en numerosas representaciones de la antigüedad, entre las que cabe señalar un fresco procedente de Herculano, conservado en el Museo Nacional de Nápoles (LIMC 1986b, 158), y un mosaico en el que una ménade sostiene al niño sobre el tigre (1986b, 174). También hay un relieve del Louvre con este tema (Reinach 1930, pl. 139, 141). En la Hispania romana aparece especialmente en la sigillata hispánica de Andújar (García 1991a, 2.3.1, 2.3.2 y 2.3.3).

Las lucernas hispanas que presentan este tipo de representación (n. $\left.{ }^{\circ} 12-13\right)$ se insertan en el marco tipológico y cronológico ya comentado. No se trata de un motivo común, pues sólamente tenemos constancia de un paralelo en Cartago, sobre una Dressel 11 (Amaré 1988, 67).

En cambio, la representación de la disposición del infante que se recuesta sobre un felino en una postura muy similar a los Mitras sacrificiales (motivo 1.4), está menos testimoniada, a lo que se añade la indeterminación a la hora de identificar la figura humana bien con Baco niño o bien con un erote báquico, posiblemente alado, si bien es confusa la figuración del ala tras la espalda. Un eros alado se representa en un mosaico de la Casa del Fauno de Pompeya (LIMC 1986b, 258). Este motivo, que hemos identificado como Baco apoyado sobre pantera, del que conocemos una pieza procedente de Segobriga, que se centra en el s. I d. C., si bien la tipología de la pieza no es determinable, dado el carácter fragmentario de la misma. No obstante, el motivo no ha sido identificado como báquico, sino como escena erótica entre joven y felino (Abascal 1989, 314). También tenemos documentado otro ejemplar procedente del Tossal de Manises, 
que sí ha sido asociado al mundo dionisíaco (Olcina y otros 1991, 44) apoyándose, desde un punto de vista iconográfico en una pieza de Vindonissa. Todas estas piezas pues se ajustan a tipos recurrentes en el s. I d.C. (n. $\left.{ }^{\circ} 14-15\right)$.

La representación entronizada de Baco de $\mathbf{1 . 5}$ es bastante frecuente en el mundo romano, como evidencia por ejemplo en un fresco del Museo Nacional de Nápoles, procedente de Pompeya (LIMC 1986b, 28). En este tipo el dios aparece representado con tirso en la mano derecha y jarra en la izquierda, vertiendo el licor para una pantera (LIMC 1986b, 25; 1986a, 140). Asimismo lo podemos identificar dentro de un marco arquitectónico y realizando exactamente la misma función antes mencionada, pero en este caso es la mano derecha la que vierte el líquido y la izquierda se apoya sobre un fuste de columna, apareciendo el torso como fondo de la escena (Tram Tam Tihn 1964, 12, n. ${ }^{\circ}$ 134) ; todo esto nos induce a pensar que en esta placa argéntea (Figura 3A) se ha plasmado un modelo escultórico marmóreo, pues la existencia de un fuste estaba destinada a proporcionar estabilidad a la figura. En esta misma pieza se puede apreciar con nitidez el marco arquitectónico en el que se encuadra la figura del dios, mientras que en el caso de nuestras lucernas, la simplificación del motivo no permite una nítida distinción de los elementos arquitectónicos, que sin embargo aparecen claramente identificados por Bailey (1980, Q1248). Amaré (1987a, 43 f.4; Figura 3B) cree apreciar a los pies del dios la figura de un animal. Caso de ser cierto, hecho que no podemos asegurar dado el estado fragmentario de la pieza, se trataría de una pantera. En caso contrario, podría formar parte del motivo arquitectónico que hace de fondo de la escena. La misma disposición es propia de los Diónysos de línea praxitélica representados en el s. II d.C. en escultura. Como paralelos en el mundo de las vajillas finas de mesa de época altoimperial (Terra Sigillata) nos encontramos esta misma disposición en varias piezas publicadas originalmente por Oswald (1936-37, Nos. 564, 567a y 574a; Figura 3C). Pero ninguno de ellos se corresponde a este tipo, que lleva su mano izquierda hacia la cabeza. Si por una mayor nitidez de la pieza apreciáramos si coloca la palma de la mano sobre la cabeza estaríamos ante un motivo de origen oriental de profundo sentido religioso; cabe citar aquí todas las piezas recogidas en el LIMC (Dyonisos-in peripheria orientali) en el apartado A de Diónisos en pie, imberbe, con las piernas cruzadas y una mano sobre la cabeza (1986a, apdo. 2.1). Si bien superan casi todas el s. III d.C., son testimonio de una tradición que en occidente tuvo una vida más corta. En Grecia y Roma aparecen figuras así, como las cabezas del Agora de Corinto (LIMC 1986a, 200a) o la del Santuario de Liber en Acquatraversa (1986a, 125). De nuevo en terra sigillata apreciamos este motivo (Oswald 1936-37, n. ${ }^{\circ} 577$ a y 578 b ; Figura 3D).

Pero, hechas estas consideraciones, nos ha parecido una iconografía más cercana al tipo del Baco de los frescos de la Villa dei Misteri de Pompeya o los Sátiros del Albertinum del Museo de Dresde, los del Museo de las Termas en Roma o de un tipo representado en Hispania por el Baco broncíneo de Pinedo (García 1991a, 5.3.4), que no es otro que el del Stibadeion de Delos; todos ellos de herencia helenística, como el Diónysos lánguido y afeminado de los perfumes y el lujo. Véanse los modelos, acompanados de Ariadna, de la terracota de Mirina, de mediados del IV a.C, en Museo del Louvre 


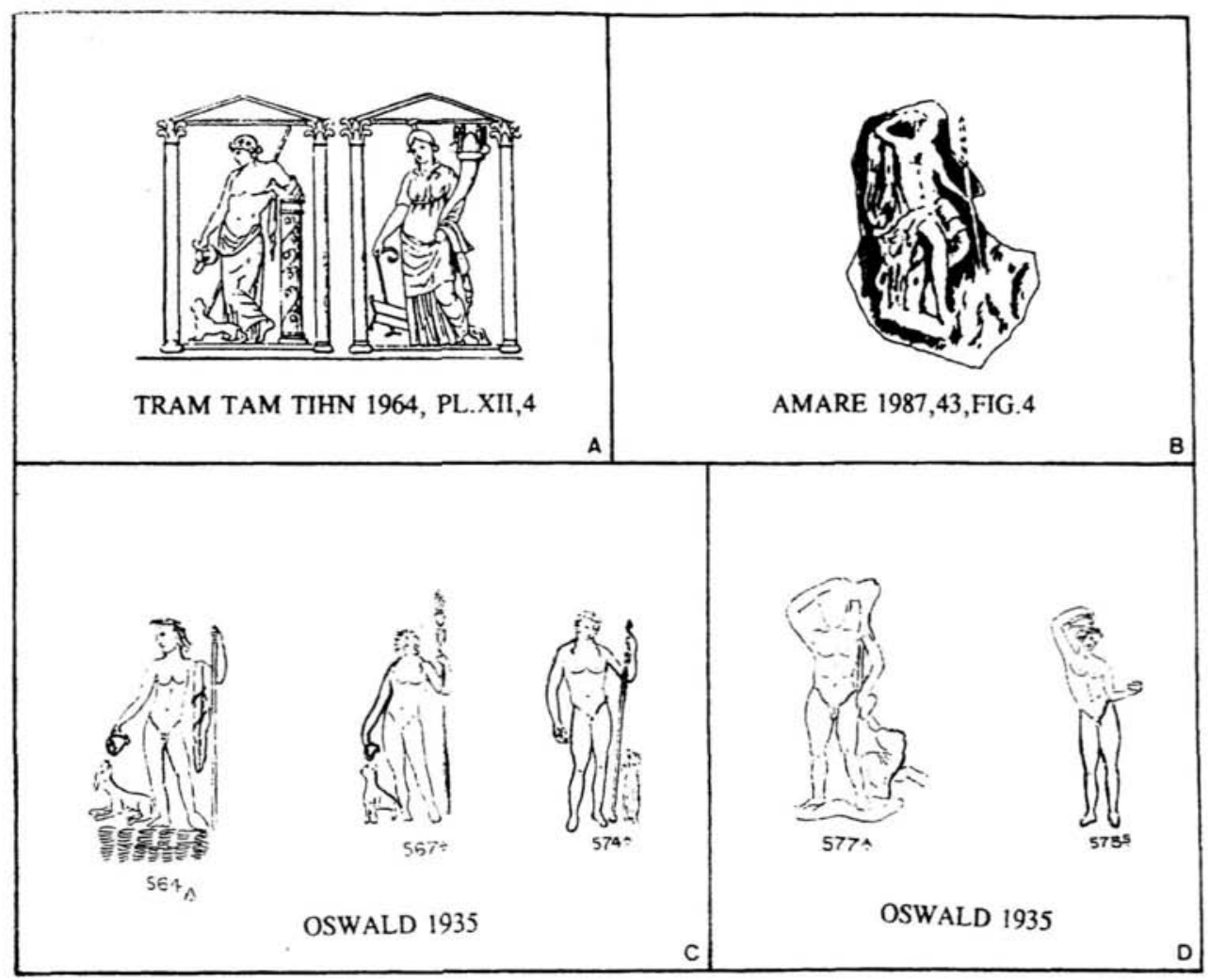

Figura 3. Baco y Ariadna (A), y diversas representaciones de Baco

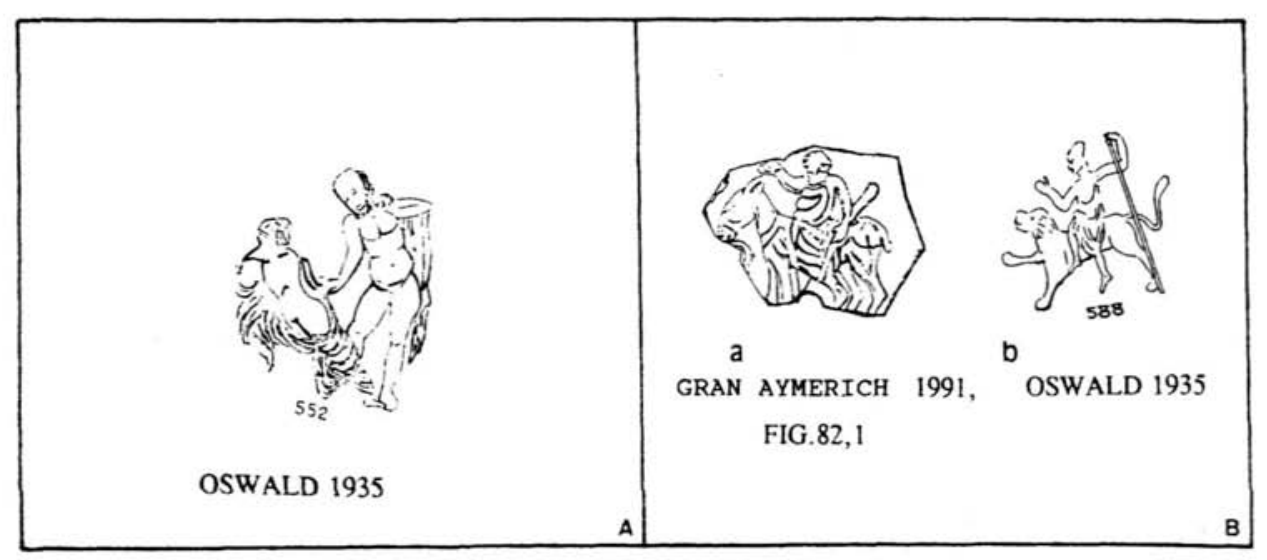

Figura 4. Baco y Ariadna (A), y representaciones sobre équidos (B) 
(LIMC 1986a, 754), o la célebre crátera de bronce de Salónica del Museo Arqueológico de Derveni, fechada en el 330 a. C., recogida recientemente en el LIMC (1986a, 755). Al margen de la iconografía báquica, coincide en las disposición corporal de estos modelos, el conocido fresco de Hércules y Telefo del Museo de Nápoles hallado en la basílica de Herculano.

Conocemos lucernas con este tipo de representaciones en la colección del Museo Británico, concretamente sobre una pieza itálica del tipo Broneer XXI que encuentra paralelos en algunos contextos de limes germano (Bailey 1980, 15, Q1248). En Hispania conocemos uno $\left(\mathrm{n} .^{\circ} 16\right)$ procedente de Calahorra. El repertorio formal es amplio, pues conocemos piezas decoradas con este motivos desde inicios del altoimperio, en formas de la familia de las lucernas de volutas, hasta prácticamente el s. III, pues también se documenta en alguna pieza de tipo cordiforme (Dressel 28). Por tanto, y como ya ha sido apuntado (Amaré 1987a, 43), la perdurabilidad del motivo es amplia.

El tipo $\mathbf{1 . 6}$ se corresponde con una dilatada historia mítica de Diónysos y Ariadna, tras su rescate en Naxos. Es bien conocida la representación clásica del hallazgo de ésta por Dionisos (como en el conocido mosaico emeritense (García 1991a, n. ${ }^{\circ}$ 992) o por un Sátiro (Oswald 1936-37, n. ${ }^{\circ}$ 552; Figura 4A). Aquí ella aparece con el tirso como una iniciada, hecha esposa del dios. El relieve de un altar del Museo Vaticano (LIMC 1986b, 193) es de idéntica representación, si bien el tema aparece en Grecia en vasos áticos del s. IV $\mathrm{aC}$ (1986a, 719 y 720 ). Señalaremos que se han dado otras interpretaciones a este grupo, paralelamente a la propuesta, como la de Moreno (1991, 427, mot.77), que considera la composición además como tal vez del tipo "Sátiro y Ménade". Los paralelos de este motivo son múltiples (Moreno 1991, 427), distribuidos geográficamente por todo el imperio.

También en el mundo lychnológico se trata de un tema de gran aceptación, pues conocemos ejemplos procedentes de Berlín, Vindonissa, Magdalensberg, Cartago y Chipre. En todos estos casos el único tipo documentado es el Loeschcke IB (= Dressel 9B), que como sabemos es de volutas y circunscrito a la primera mitad del s. I d.C. También nuestra pieza cordobesa puede situarse en este contexto $\left(n .^{\circ} 17\right)$. La presencia de algunos atributos en determinadas piezas de primera generación y por tanto con una gran calidad en los relieves han permitido a Bailey considerar este motivo como una pareja de Sátiro y Ménade, al igual que, siguiendo a este autor y como ya hemos indicado realiza la Dra. Moreno. Sin embargo, el propio Bailey identifica una escena de un punzón similar como Dionysos y Ariadna (1988, 9-10, Q1893), citando además paralelos griegos y germanos. Nosotros, sin embargo, dada la documentación de paralelos en otros campos artísticos que evidencian claramente la iconografía de Baco y Ariadna, hemos optado por esta interpretación.

Pasando a la representación satírica, en cuanto a bustos se refiere, se nos ofrecen dos tipos muy distintos: la del Sátiro de rostro demoníaco (Mansuelli 1958, 540) y la del Sileno de rostro apacible, marcado por una ancianidad tan venerable como marcada por los excesos, de grandes cuencas oculares y abundante cabello y barba. Como copia de un tipo de Calamis, conocemos una escultura marmórea del Museo Nacional de Nápoles 
(LIMC 1986a, 185) con las mismas características iconográficas que la aludida. En Hispania poseemos algun ejemplar de estas características, como los presentados por Rodríguez Oliva, procedentes de Málaga (1978, 65-72).

Restringiéndonos al caso de las lucernas, el busto de Sátiro (Tabla 3) lo tenemos documentado en Hispania en yacimientos tanto béticos como lusitanos y tarraconenses (n. ${ }^{\circ}$ 18-24). La icononografía es variada, y por tanto, la cantidad de punzones también lo era. Hemos preferido agrupar todas estas pequeñas variantes estilísticas en un mismo apartado, a fin de no hacer excesivamente amplio el índice de motivos. Todos ellos se ajustan de nuevo a tipologías de volutas/disco, en las que optamos por las primeras tal y como tenemos documentado en la pieza n. ${ }^{\circ} 22$, sobre una Dressel 15 y en la n. ${ }^{\circ} 24$, sobre una lucerna de volutas de tipo indeterminado. No obstante, en el caso de la pieza n. 21 sí tenemos un ejemplo evidente de lucerna de disco (Dressel 20), si bien no debemos olvidar que se trata aún de las primeras producciones de estas características, y por tanto sincrónicas a las lámparas de volutas.

Por su parte, el busto de Sileno lo tenemos asociado a 2 piezas (n. ${ }^{\circ} 25-26$ ) que cronológicamente se sitúan en un contexto algo más tardío: el tipo de la primera de ellas comienza a producirse en talleres centroitálicos desde mitad del s. I d.C. circa, al tiempo que el otro está presente en una Dressel 24 típicamente del s. II d.C. , y ésta última posiblemente procedente de un taller africano. Esta cronología más tardía para el motivo del busto de Sileno aparece asimismo refrendada por otras representaciones en el imperio, una buena parte de ellas del tipo Loeschcke VIII y algunas asociadas al taller de Luccei (Bailey 1988, 9-10), que es una figlina típicamente africana, de la zona del Túnez actual, activa de época tardoantonina-severa (Bailey 1988, 98). Se trata por tanto del motivo de cronología más tardía de todos los aquí tenidos en cuenta.

Pasando a otros tipos, podemos reconocer cinco tipos de actitudes de Sátiros en medio de la actividad frenética de los cortejos báquicos:

- (2.2) bien extenuados por la danza y el vino, en actitud desequilibrada respecto a los miembros y sosteniendo un cántaros ya vacío. Un prototipo bien conocido es el del Diónysos sostenido por Bacante que se deja caer, sosteniendo un bárbiton, con claros paralelos en cílicas áticas de figuras rojas (LIMC 1986a, 720). Nosotros hemos podido recoger exclusivamente una representación de estas características, procedente de las terreras de Lo Campano (Cartagena), y sobre una lucerna de forma indeterminada ( $n .^{\circ} 27$ ). Es un motivo que no gozó de gran predicamento, tal y como evidencia la escasez de paralelos en lucernas. Se trata de una composición en la que el Sátiro sostiene el cántaros en una mano, y en la otra lleva un tirso. Este último no es perceptible en el ejemplar hispano, dado su estado fragmentario, pero la identificación general de la escena ha sido correcta (Amante 1988, 223), al confrontarla con una pieza del British Museum, que ha su vez aporta otro paralelo (Bailey 1980, Q819). El tipo de lucerna que alberga estas representaciones es el Loeschcke IB. Por tanto, unido al dato anterior, el intervaio de frecuencia de este motivo debemos situarlo, a la luz de los datos con que contamos en este momento, en la primera mitad del s. I d.C. 
- (2.3.) bien en actitud danzante. Circunscribiéndonos al campo de las lucernas, las representaciones de satiros danzantes son muy frecuentes. Y por tanto, la variabilidad de punzones diferentes también lo es. Normalmente siempre llevan asociado algún atributo (cántaros, tirsos, nébrida...), y los tipos a los que aparecen asociados suelen limitarse al s. I d.C. (Bailey 1980, 17-18). Nosotros no procedemos a desglosar este apartado motivo por motivo ya que la fragmentariedad de nuestras piezas nos impide precisar la exacta representación de cada uno de ellos. También estas piezas hispanas se adaptan al marco cronológico antes citado ( $\mathrm{n}^{\circ}$ 28-34).

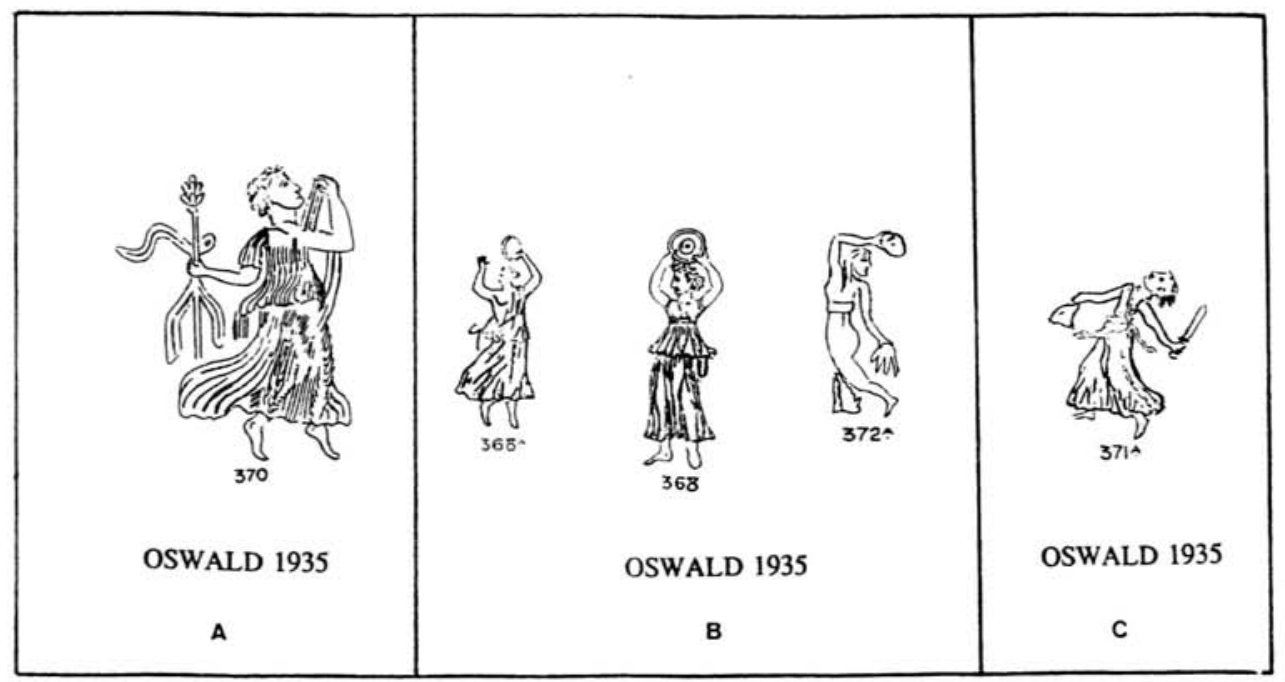

Figura 5. Representaciones de ménades en diversas actitudes

- (2.4.) bien sosteniendo en actitud danzante una copa de la que sale fuego para iluminar las fiestas de Baco celebradas en la nocturnidad, si bien estamos más acostumbrados a ver al cortejo blandir antorchas, como en la figura de Baco en banquete en una crátera de campana del Museo Nacional de Nápoles (LIMC 1986a, 354). Si bien en lucemas hispanas sólo hemos localizado una pieza que se pueda incluir en esta variante iconográfica (n. $\left.{ }^{\circ} 35\right)$, la gran cantidad de paralelos que conocemos diseminados por todo el imperio, tanto por el Mediterráneo como por el limes renano (Moreno 1991, 473) nos induce a pensar en la aceptación de esta representación. Este motivo ha ocasionado controversias, pues ha sido identificado en algún caso como Prometeo - para la correcta interpretación del mismo remitimos a las precisiones aportadas por Bailey $(1980,19)$ —. Aparece asociado siempre a tres formas: la Loeschcke I, la IV y la VIII. Esto nos induce a considerar el s I d.C. el más prolífico en cuanto a contextos con lucernas de estas características. No obstante, no faltan paralelos del último de los tipos citados, algunos de los cuales podrían ubicarse plenamente en el s. II d. C., sobre todo aquellos procedentes de contextos provinciales. En estos casos, suele tratarse de copias manufacturadas localmente, con lo cual la perduración es mayor que en los yacimientos de la Península Itálica (Bailey 1980, 19-20). 
- (2.5) o corriendo con tirso en la mano y con una nébrida que ha dejado de cubrir la desnudez del Sátiro. Es esta una figuración de tipo neoático, que nos recuerda a las figuras de las aras del Teatro de Itálica, publicadas con extensión por J.M. Luzón (1978, 272-284), con un comentario al que aludiremos más adelante para las piezas de nuestros tipos de ménades danzantes. Otros prototipos semejantes pueden hallarse en algunas cílicas áticas de figuras rojas, como una procedente de Vulci (LIMC 1986a, 470). La disposición de la capa está también recogida en varias piezas cerámicas áticas, como por ejemplo en la crátera de cáliz del Museo del Ermitage (LIMC 1986a, 621). En lucernas lo encontramos asociado en la Península Ibérica a los tipos Dressel 9a y 20 (n. ${ }^{\circ} 36-38$ ), marcando un intervalo que oscila del s. I a la primera mitad del s. II d.C. El resto de paralelos que conocemos, sin embargo, se centran en el tipo Loeschcke I, y por tanto no sobrepasan el s. I d. C. (Bailey 1980, 18).

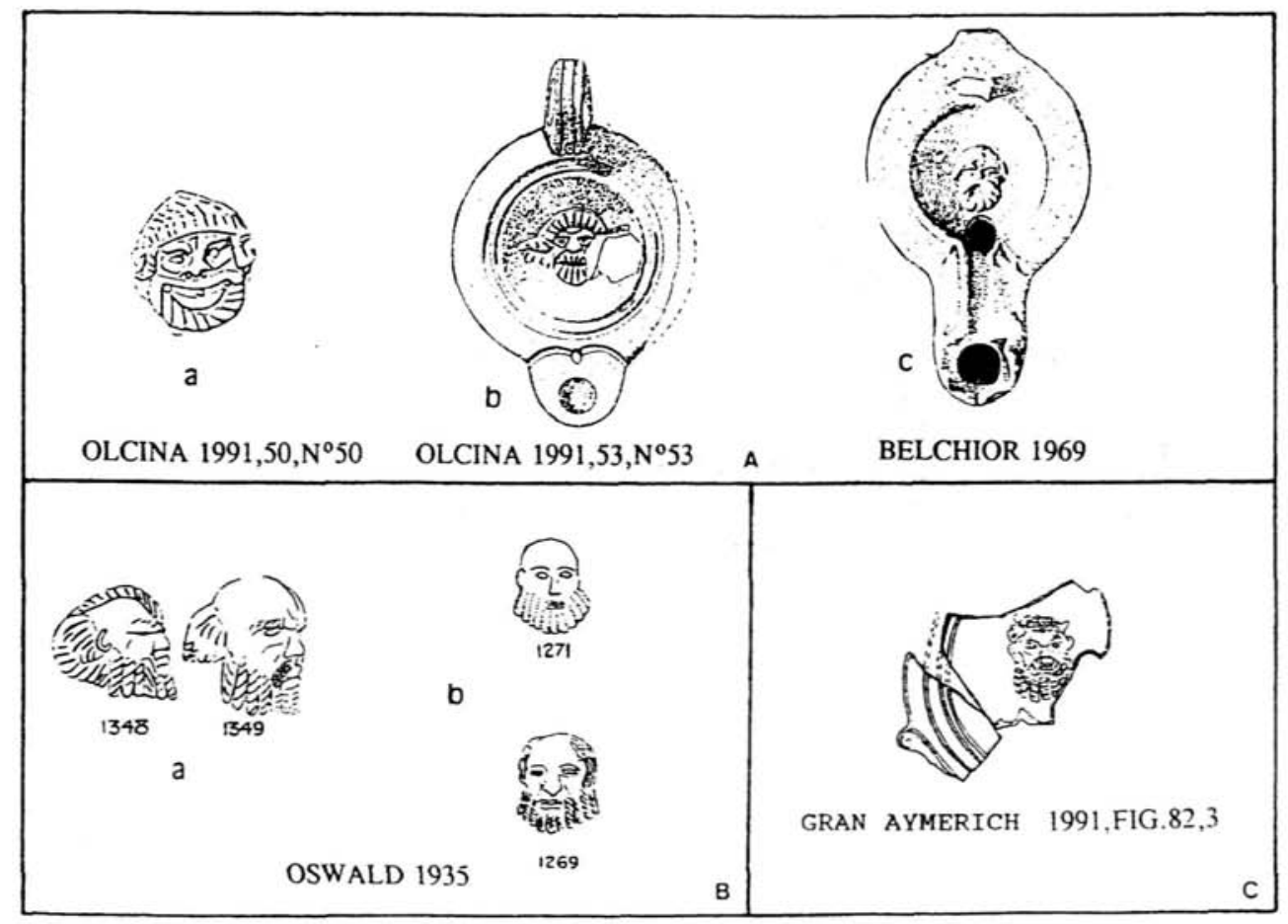

Figura 6. Representaciones de máscaras

- (2.6) o en una actitud ya derrotada, con el sátiro tumbado en actitud descuidada, sobre un odre. A. Balil, comentando la figura idéntica de Caesaraugusta (García 1991a, 8.2.9), cita numerosos prototipos, en el ámbito pergaménico, en relación con figuraciones de Paposilenos o Ariadna en Naxos, o bien en el más propiamente romano (tipo Virunum de Ninfas, Sátiros de Adrianópolis, del Teatro dei Falerii, etc...). El tipo de 
Sátiro yacente sobre odre lo tenemos documentado en 5 piezas hispanas (n. ${ }^{\circ} 39-43$ ). De ellas, aquellas de las que podemos extraer datos sobre su tipología, se limitan a la forma Dressel 11, constituyendo piezas de importación itálica halladas en un pecio en las Baleares (Domergue 1966, 26). Este motivo no está recogido en la caracterización iconográfica de Bailey. La pieza procedente de las termas de Segobriga (n. ${ }^{\circ}$ 39) tampoco fue considerada como de tema báquico. Los paralelos parecen apuntar a una cronología situable en la primera mitad del s. I d.C. (Abascal 1989, 306).

- (2.7) en el cual el Sátiro aparece en la postura de macerar las uvas en la vendimia, si bien el recipiente que aparece nos hace dudar de su labor, pues no reconocemos prototipos para él. Sirva de exponente de los numerosos sátiros vendimiadores el del ánfora de Figuras Rojas del tipo B (540-530 a.C.), del Museo de Basilea, en idéntica disposición corporal (LIMC 1986a, 408). Este sí es un tema muy frecuente que decora los discos de las lámparas romanas, y de este mismo motivo conocemos diversas variantes, como consecuencia del uso de moldes impresos con punzones diversos (Bailey 1980, 17, Q815-6). Las dos piezas que nosotros hemos podido encontrar ( . $\left.^{\circ} 44-45\right)$, ámbas de Segóbriga, son de lucernas de cronología indeterminada. Por analogía a los paralelos iconográficos localizados en el British Museum, del tipo Bailey A, centramos la escena en el s. I d. C., pues el resto de paralelos conocidos, al estar en estar fragmentario, no contribuyen a precisar la cronología (Bailey 1980, 18).

- (2.8) el Sátiro aparece en postura itifálica, y junto a él una Ménade tocando el tympanon ( . $\left.^{\circ} 46\right)$. No es un motivo muy común, y se centra en el s. I d. C. De él conocemos varios paralelos, sobre todo en Italia (Moreno 1991, 610).

- (2.9) este motivo de Sileno sobre asno no es muy frecuente en la decoración de las lucernas hispanas. Hemos documentado exclusivamente una pieza procedente de Málaga (.$^{\circ} 47$ ), sobre un tipo de volutas-disco indeterminado. En esta representación, el autor identifica al personaje como un Sileno vestido con un odre y con el pedum en su mano derecha (Gran Aymerich 1991, 110, fig. 82,1). Nosotros no advertimos con nitidez en la representación el odre que recubre el torso del Sileno. Esta observación tampoco viene avalada por la tradición iconográfica, donde es un elemento telar el que sostiene descuidadamente el jinete báquico, nunca un odre ${ }^{8}$. Resulta asimismo incierta la identificación de un personaje báquico sobre tigre en el caso de un fragmento de disco de lucerna recogido por Domergue $\left(1966,37\right.$, n. $\left.^{\circ} 96\right)$. En él se puede apreciar una figura humana sobre cuadrúpedo, apoyándose en el elemento vertical que pudiera ser considerado tanto una lanza como un tirso, en función de la atribución iconográfica del jinete. Sin embargo, las representaciones habituales de personajes báquicos (Silenos-Sátiros) sobre animales no ofrecen una sobriedad como la apreciable en esta escena, que como bien señala

${ }^{8}$ La referencia al Daremberg-Saglio que aporta el autor (Gran Aymerich 1991, 110, nota 216 ), en la que alude a la frecuente aparición de este tipo de representaciones es errónea, debiendo corregirse el tomo IV/ 2 por el tomo IX. 
Domergue posee un carácter más heroico. Una pieza similar a ésta puede verse en la Figura $4 \mathrm{Bb}$, en la que aparece yuxtapuesta a nuestra pieza n. ${ }^{\circ} 47$ (Figu-ra $4 \mathrm{Ba}$ )..

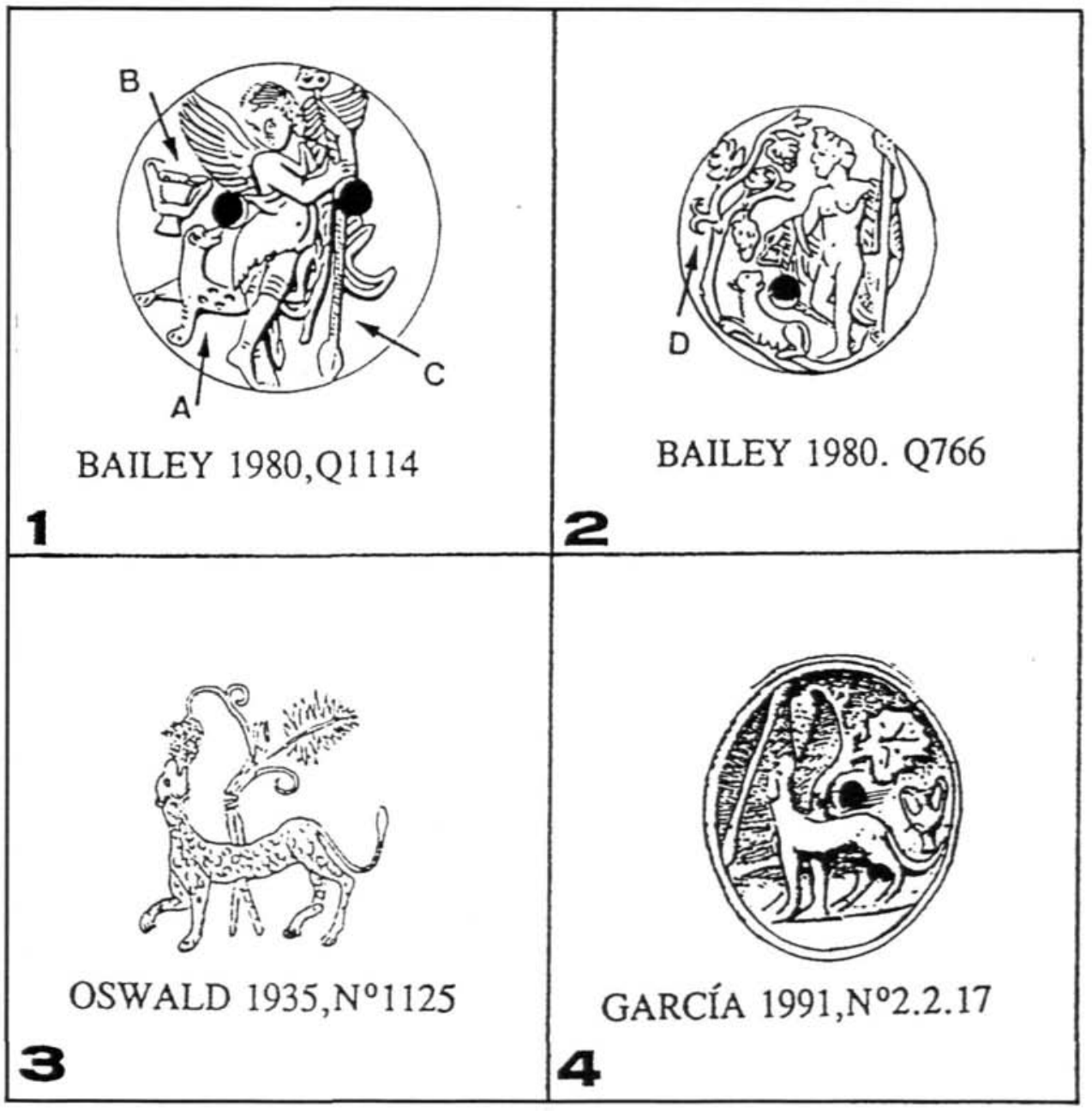

Figura 7. Diversas representaciones que evidencian la costumbre de retocar los motivos a punzón por parte de los alfareros

Se halla vinculado con este tema el de la conducción de Hefesto al Olimpo en asno, con una amplia tradición tanto mitográfica a partir de Pausanias (I, 20,3), como iconográfica, en la que el Vaso François ocupa un lugar preeminente, destacando asimismo las acunaciones de Mende (Calcídica) en este tipo de representación, en la cual Sileno se presenta sentado con una orientación opuesta a la marcha del asno, tal y como se muestra en una lucerna conservada en el British Museum (Figura 8, Q772). 


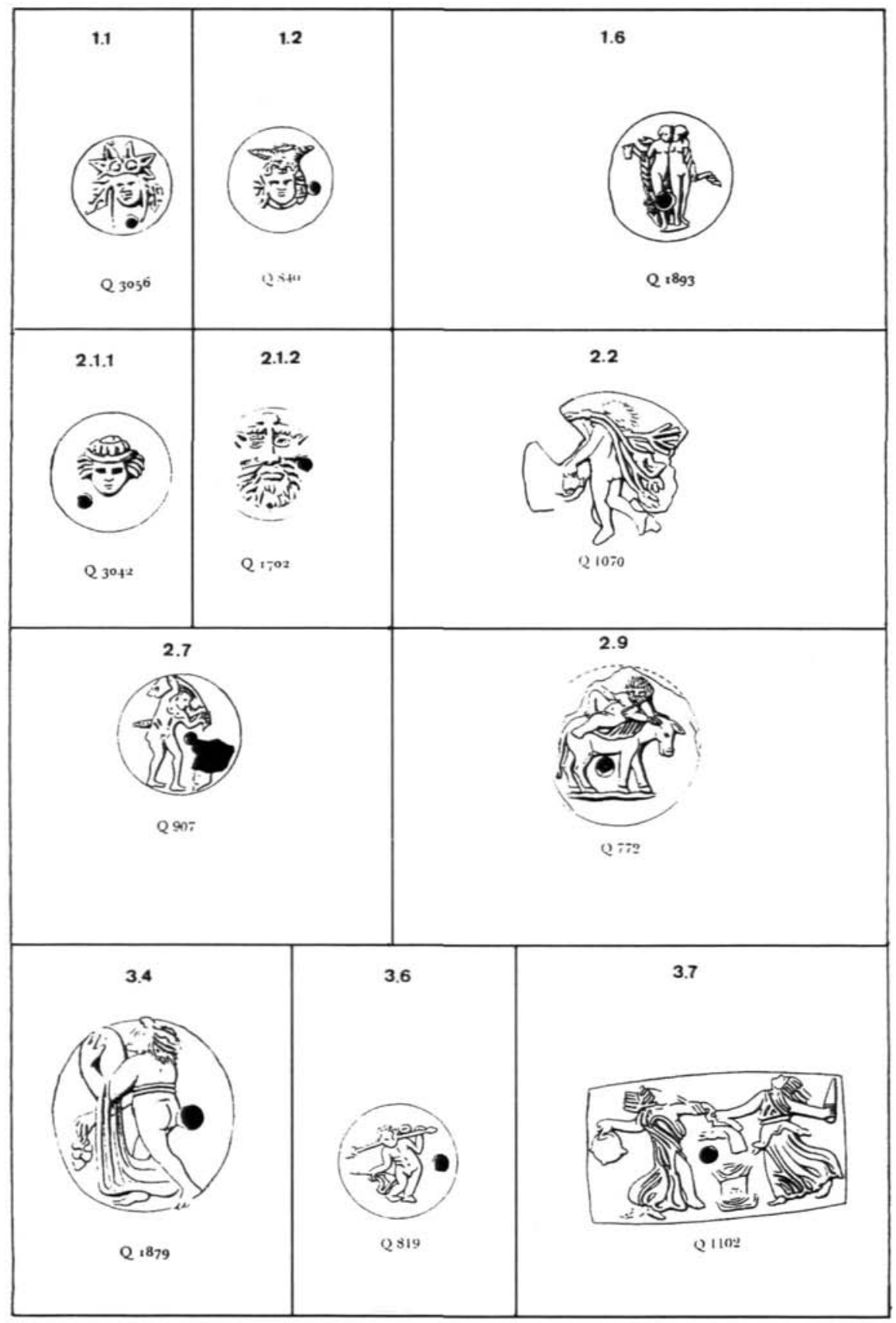

Figura 8. Representaciones háquicas no documentadas en lucernas hispanas 
No extraña, por otro lado, la presencia de este animal ${ }^{9}$ asociado al mundo dionisíaco, pues ocupaba un lugar destacado en el transporte de los racimos en la vendimia. Para ampliar referencias remitimos al citado volumen del Daremberg-Saglio (IX,p.1091 y 1099, n. $\left.^{\circ} 37\right)$.

Refiriéndonos ahora a las representaciones menádicas, en casi todas debemos tener presentes las ya citadas que aparecen en las aras neoáticas de Itálica. El motivo 3.1 trata de agrupar todas aquellas representaciones de ménades danzantes que, dado su estado fragmentario, no podemos incluir en uno u otro grupo: son dos las piezas que hemos localizado ( $\mathrm{n}^{\circ}$ 48-49), y como en otros caso que ya hemos visto, la cronología de las mismas es altoimperial, sin que podamos precisar más.

No todos los tipos son identificables, como el 3.2, pero responden a la misma sensibilidad artística. Curiosamente esta variante tampoco es recogida por Bailey, cuando dos de las tres piezas con que contamos $\left(n .{ }^{\circ} 50\right.$ y 52$)$ son claramente piezas itálicas de importación. En la de Tarragona el relieve de los motivos es notable, debiendo por ello considerar a esta pieza como de primera generación (Bernal 1993b, n. ${ }^{\circ} 64$ ). Sin embargo, en otros casos, en los que el relieve no es de tan buena calidad, no se han podido identificar los crótalos que lleva la ménade en la mano izquierda, si bien hay que reconocer que la cantidad de paralelos existentes ofrece no pocos ejemplos nítidos (Moreno 1991, 607).

En lo que se refiere al motivo $\mathbf{3 . 3}$ podemos afirmar que la disposición de la Ménade es idéntica a la de una figura femenina perteneciente al Santuario de Aigión, tal y como la vio Pausanias $(7,23,9)$ y que aparece representada en LIMC (1986a, 343). El tipo aparece de igual modo en los relieves romanos del s. I. d. C., representado en un sátiro en idéntica actitud (García 1991a, 10.2.3) en una pieza de origen italiano y en varias piezas de Terra Sigillata de época altoimperial (Figura 5A). Nuestra lucerna n. ${ }^{\circ} 53$ es una pieza excepcional, y por ello la hemos incluido en el catálogo, a pesar de proceder de Mauritania Tingitana. Es una pieza itálica de importación de un taller posiblemente centroitálico, de gran calidad y notables dimensiones, y que en las margines aparece decorada con hojas de hiedra (Bernal 1995, n. ${ }^{\circ} 12$ ). Este motivo no es muy frecuente en el mundo romano occidental, si bien conocemos ejemplares procedentes de Sidi Khrebish, Asia Menor y Egipto (Bailey 1980, 17, Q 905). Los tipos en los que aparece (Dressel 11, 15 y Broneer XXV) indican que debemos ubicarlo en un intervalo cronológico al menos del s. I - primera mitad del s. II d.C.- Nuestra pieza procedente de Ceuta debemos situarla en un momento no muy avanzado de mediados-tercer cuarto del s. I d.C.

La ménade del motivo 3.4. nos hace recordar, entre otras (Figura 5B) a las que Luzón numera como 1A, 2B 3B en su citado artículo. De igual modo para la 3.7 nos dirigiríamos a las $1 \mathrm{C}$ y $3 \mathrm{C}$. El motivo 3.4, presente en una pieza procedente de Barcelona (n. ${ }^{\circ} 54$ ) y otra de Peroguarda (.$^{\circ}{ }^{5} 5$ ) debemos datarlas en un intervalo amplio, al carecer de elementos que contribuyan a fijar su cronología, ya que la última pieza de contexto

9 Desarrollado ampliamente como -monture habituelle de Silène- en el Daremherg-Saglio, vol . 1/I, p. 621 . 
hispano es indeterminada ( . $^{\circ}$ 56). Bailey también aporta algún paralelo $(1988,10$, Q3069) que nos hace, asociándola al tipo Loeschcke VIII, ampliar su cronología al menos hasta la mitad del s. II d.C. En esta pieza (la de Peroguarda) creemos apreciar una mera refacción masculina del tipo que venimos comentando, si bien, a pesar de la evidente barba que presenta, el autor habla de um bacante" (Moutinho 1976, 9).

Para la 3.5, además de la referencia anterior, nuestra mirada se remota al mundo griego, en multitud de seguidoras del dios con serpientes en sus manos, como la de la crátera de volutas de figuras rojas de Spina (LIMC 1986a, 869) o, en el mundo romano, la ménade del extremo derecho de un sarcófago del Louvre (1986b, 192). Es preciso hacer la observación de que en este caso la figura elegida para la Tabla de Motivos es la publicada por Bailey (1988, Q2378) en lugar de la dada a conocer por Amaré (1988, 68, fig. 106), dada la escasa calidad gráfica de esta última. Por otra parte nuestra apreciación confirma que el instrumento en cuestión no es un aulós sino una siringa. Este motivo lo conocemos sobre una lucerna de Arcobriga de inicios del s. I d.C. (n. ${ }^{\circ} 57$ ). También lo tenemos documentado sobre lucernas fundamentalmente de producción itálica de los tipos Loeschcke IB, IC y IV, en contextos provinciales diversos (Bailey 1988, 10, Q 2378). Se centra pues en el s. I d.C., si bien algunas formas podrían prolongarse hasta inicios de la centuria siguiente.

La ménade danzante con tirso y tympanon (motivo 3.6) la tenemos documentada en dos piezas hispanas, de cronología indeterminada ( . $^{\circ}$ 58-59). También tenemos documentado algún paralelo (Bailey 1988, 10, Q885 bis) del tipo Loeschcke V. Desde un punto de vista compositivo, es muy similar a nuestro motivo ${ }^{\circ}{ }^{\circ} 2.2$, en el que varían el tympanon es sustituido por el cántaros.

El último motivo relacionado con ménades (3.7) es el que más encontramos difundido por todo el imperio (Figura 5C). Se asocia normalmente a la forma Loeschcke I (sobre todo a sus variantes A y B), y en algún caso a la Loeschcke IV, limitándose por tanto al mundo de las lucernas de volutas. Esto se traduce cronológicamente en un intervalo preciso que oscila desde la aparición de los primeros tipos de volutas a finales del s. I a.C. hasta mediados del s. I d.C. Los paralelos son abundantísimos (Bailey 1980, 16-7, Q 787). Las seis piezas hispanas que nosotros hemos podido reunir $\left(n .^{\circ} 60-65\right)$ se insertan perfectamente en este periodo, pues tenemos una de muy principios del s. I (n. ${ }^{\circ} 63$ ) hasta la más tardía de ellas, la Dressel 11 gaditana $\left(n{ }^{\circ} 60\right)$. En este caso, dada la asociación en todos los ejemplos conocidos con decoración de estas características a ejemplares de volutas, podemos considerar la pieza de tipología indeterminada n. ${ }^{\circ} 62$ como también una pieza de la familia de volutas.

Pasamos ahora a ese grupo de motivos en los que aparecen representaciones de tipo faunístico, concretamente panteras en diversas actitudes, que debido a su asociación con otra serie de elementos vinculados directamente con el entorno dionisíaco nos ha llevado a considerarlas asimismo como relacionadas con el mundo báquico (Tabla 5). Entre los paralelos del motivo de la Pantera(s), en el primer caso (4.1) cabe aludir a dos monedas romanas de Clunia, en las que en lugar de la cílica aparece una letra I, con la inscripción Libero al dorso (Gurt 1985, nos. 735 y 748). Porcentualmente es éste el mo- 
tivo de pantera de representación más prolífica en lucernas, y así en Hispania lo tenemos documentado sobre 8 piezas. El motivo está compuesto por una pantera con sus dos extremidades delanteras alzadas y apoyadas sobre una crátera que, en aquellas piezas de primera generación que sí permiten observar la calidad del relieve, aparece llena de racimos de uvas. La identificación de este cuadrúpedo como pantera y no como cualquier otro tipo de felino es evidenciada por la presencia en alguna de las piezas de círculos incisos a todo lo largo de la piel del animal, tratando de darle una apariencia de aspecto a manchas, lo que abriría la posibilidad de tratarse de un tigre, animal del cortejo báquico que figura al paso conquistador de Diónisos por la India, arquetipo de Alejandro. La vinculación de este motivo al mundo mitraico, tal y como se ha querido ver en algún caso, identificando el felino como un león no nos parece apropiada, tal y como a este respecto aporta Amaré $(1988,69)^{10}$.

El motivo de la pantera se documenta bien de manera aislada (Bailey 1980, Q1327 y Q1391), bien asociada a Baco y a atributos báquicos respectivamente, como hemos podido documentar en otros casos (motivos 1.1.3 y 6). Respecto al intervalo cronológico de frecuencia, optamos por el s. I - principios s. II d.C.-, y directamente asociado a las lucernas de la familia de volutas. Se ha llegado a prolongar su pervivencia hasta el s. IV d. C. (Moreno 1991, mot. 53, láms. XLI-XLII), pero nosotros carecemos de testimonios que nos permitan ampliar hasta fechas tan recientes este intervalo de aparición.

Es interesante observar cómo todas ellas ( $\mathrm{n}^{\circ}$ 66-73), si bien dentro de un contexto altoimperial, parece que se ubican en un espacio temporal del s. I, pero no en los primeros momentos de esta centuria. Así lo parecen indicar la documentación de los tipos Dressel 11,12 y 15 , y sobre todo la ausencia de los típicos fósiles directores de época augustea-claudia/flavia (Dressel 9A,B), tal y como sí tenemos documentados para otros motivos. Para los paralelos norteafricanos son interesantes los datos publicados por Moreno $(1991,402)$ y para el resto del imperio los de la colección del Museo Británico (Bailey 1980,$73 ; 1988,68-9)$.

Para el segundo motivo, constituido por dos panteras afrontadas apoyadas en una crátera (4.2), es interesante contrastar el Sarcófago del Museo de las Termas (Cumont 1966, 158, fig. 26) o un mosaico de Alcalá de Henares, publicado con un amplio estudio por Fernández Galiano (1984). Lo tenemos documentado en una sóla pieza procedente de Baelo Claudia $\left(\mathrm{n} .{ }^{\circ} 74\right.$ ) y recogida posteriormente en la catalogación de todas las piezas béticas (Moreno 1991, 403, mot. 54). Representaciones análogas del mismo motivo, pero con una cierta variación en la proporción de los elementos panteras/crátera, las hallamos

${ }^{10}$ Rodríguez Neila (1978-9, $42, \mathrm{n}^{\circ} 30$ ) al referirse a la pieza cordohesa con este motivo procedente de la Necrópolis de los Oficiales ( . $^{\circ} 70$ ), aporta toda una serie de paralelos iconográficos en estelas y sarcófagos que le inducen, siguiendo a Cumont, a relacionarlo con el mundo mitraico. A nuestro juicio, la presencia de manchas en el pelaje de un felino permite identificarlo indistintamente como una pantera o un tigre. En nuestro caso, es evidente que las posee. La presencia de las mismas en otras piezas (Figura 7), en las que la atribución del animal como una pantera es evidente, debido a la asociación de la misma con otros elementos de tipo báquico, nos induce a considerarla como tal. Además, la estilización que se observa en la silueta de este animal confirma esta consideración. 
también en lucernas de disco tardías, de rostrum cordiforme (Bailey 1980, Q1391). Esta lucerna es ciertamente problemática, pues se trata de un tipo de lucerna de disco, pero de atributos morfológicos no muy claros. El rostrum, elemento morfológico fundamental a efectos cronológicos en este tipo de piezas, no presenta una delimitación clara. Debemos considerarla como una lucerna de disco tardía, emparentable con las producciones de tipo cordiforme (Dressel 28) y como mínimo sincrónica de este tipo de piezas (s. II-III d.C.), si bien no es de extranar que aparezca en contextos más tardíos, asociable a piezas africanas de importación en las postrimerías del Bajo imperio. La carencia de contexto estratigráfico asociable a esta pieza, no nos permite precisar más al respecto.

En cambio el motivo fragmentario de 4.3. bien parece una asociación de motivos sin ensamblar, como en 4.1, sino por yuxtaposición. El fragmento de disco conservado permite ver una crátera y restos de una pantera $\left(n .^{\circ} 75\right)$, pero la fragmentariedad del mismo impide conocer la totalidad de la representación. No hemos podido documentar paralelos alguno de esta composición (Moreno 1991, 403).

Por lo que se refiere al apartado $\mathbf{5}$ del tipo Máscara, se trata de una representación de tradición bien documentada en Roma, que parte de las máscaras de la Grecia más clásica, fabricadas en terracota, como la procedente de la Beocia del s. v a.C. (LIMC 1986a, 16). En Hispania, baste citar la cabeza de sátiro de una estatua del proscenio del teatro de Belo (García 1991a, 8.2.12). Las máscaras constituyen un tema muy frecuente en el mundo de la cerámica en general, y centrándonos en las lucernas, la profusión de motivos es abundantísima. Este hecho es debido a soluciones de tipo tecnológico, pues se trata de motivos figurados de pequeñas dimensiones y fácilmente retocables al salir del molde, pues no se trata de composiciones complicadas. Las máscaras las tenemos documentadas en tipos tanto de producción típicamente noritálica (caso de las Firmalampen ${ }^{11}$ ), centroitálica ${ }^{12}$ así como africana (Deneauve XA), en un abanico cronológico que oscila desde el s. I hasta finales del s. III d.C., en numerosas ocasiones formando composiciones de elementos cómicos y trágicos. Centrándonos en el caso que nos ocupa, las máscaras de tipo báquico también son frecuentísimas, y exponente de ello es la aparición en Hispania de 11 piezas con este tipo de representación, hecho que convierte a este motivo en el más documentado de todos los báquicos que hemos podido localizar en la Península Ibérica (n. ${ }^{\circ} 76-86$ ).

Dos son los tipos que se nos ofrecen, de los cuales el primero,denominado Máscara frontal exenta, es mayoritario, mientras que el segundo queda reducido a una pieza como exponente de otras que puedan sumarse en un futuro a él dentro de la tipología Máscara lateral con soporte. Como prototipos de éstas últimas destacan las máscaras griegas del "Diónysos Psilax ${ }^{13}$. Los abundantes mosaicos de época helenística

${ }^{11}$ Baste como ejemplo el caso de la pieza $\mathrm{n}^{\circ} 178$ del catàlogo de los materiales procedentes de Conimbriga (Belchior 1969, 71, est. XXI,1).

12 Como la lucerna del tipo Dressel 20 procedente de Ampurias y conservada en el Museo Arqueológico de Gerona (Palol 1948-49, 251, n. ${ }^{\circ}$ 57, fig. 107.57).

${ }^{13}$ Según las referencias contenidas en el Daremberg-Saglio (1/1, 617, fig. 694). 


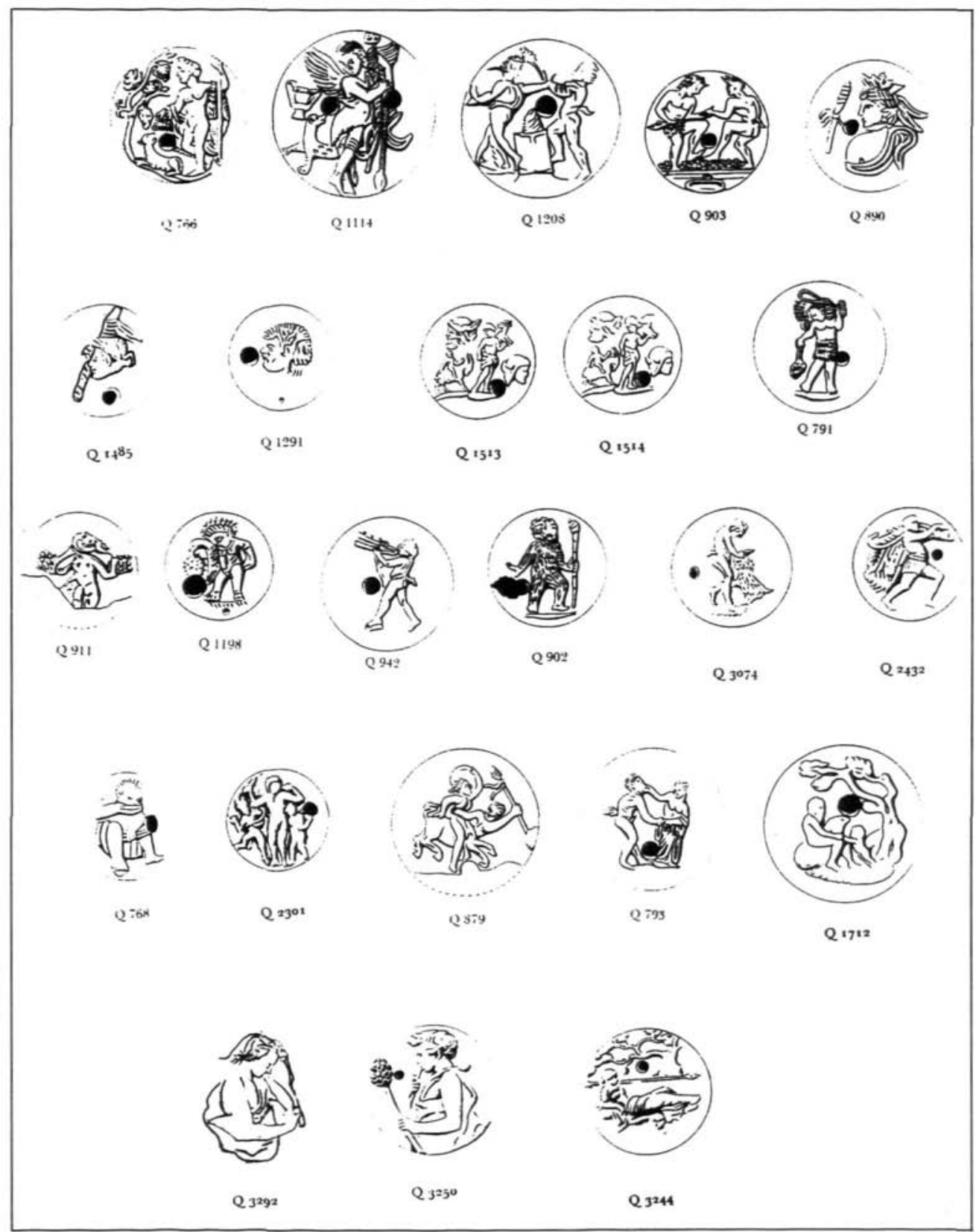

Figura 9. Representaciones báquicas no documentadas en lucernas hispanas 
de tema teatral, que en época romana se recrean, como en el conocidísimo tema de los "Preparativos del Drama. de la Casa del Poeta Trágico en Pompeya, de finales del I d.C. En la figura 6 puede apreciarse una división de las máscaras en función del tipo de soporte, encontrándose dentro del apartado A algunos ejemplos de máscaras en lucernas, y en el B sobre piezas de Terra Sigillata.

Las máscaras de Silenos aparecen asociadas en Hispania a tipos de volutas en los ejemplares reconocibles ( $\mathrm{n}^{\circ}$ 81-83), y en la gran mayoría de las piezas conocidas en directa relación con la forma Dressel 11 . En el resto del imperio también es la forma $\mathrm{n}^{\circ}{ }^{\circ}$ 11 de la tabla tipológica de Dressel la más frecuente, si bien también conocemos ejemplares asociados a los tipo Loeschcke I y Broneer XXI (Bailey 1980,19; 1988,10). Algún autor (Amaré 1988,69) restringe su aparición exclusivamente a época flavia, pero a nuestro parecer esta parcelación cronológica resulta demasiado forzada e inoperante, pues los tipos en los que se documentan este motivo varían su cronología en función de los diversos contextos .

La máscara lateral sobre plinto que hemos considerado en nuestro $n .^{\circ} \mathbf{5 . 2}$ se encuentra representada en una pieza indeterminada de cronología altoimperial procedente de Conimbriga ( $n .^{\circ} 86$ ). Por su parte, en el corpus documental de Bailey no hemos podido documentar motivo alguno directamente emparentado con el nuestro.

La última representación que hemos incluido en nuestro índice de motivos es la Pantera asociada a elementos báquicos (6). Puede tratarse del motivo 4.3 completo, pero lo incluimos en un apartado diferente pues este es el caso que más claramente ejemplifica cómo un motivo aislado no puede ser directamente asociado a la esfera dionisíaca, mientras varios atributos encadenados, o elementos báquicos asociados, sí permiten su correcta interpretación. En nuestra pieza tenemos una pantera asociada a una crátera, a una vid y a un tirso. Los paralelos de este motivo son mínimos, y no hemos documentado ningún paralelo ornamental perfecto. En cambio, sí hemos podido documentar representaciones que tienen en cuenta uno o varios de estos elementos, pero en diversa disposición o asociados a otros elementos. Sirve por tanto nuestra pieza como ejemplo evidente de la costumbre tan extendida entre los alfareros de retocar los impresores de los moldes/arquetipos o los propios moldes, con un doble objetivo:

- Mejorar la definición del motivo en el caso de que el molde estuviese en malas condiciones.

- Incluir matices innovadores que se traducen en la creación de un motivo original

En nuestra pieza (n. ${ }^{\circ} 87$ ) se observa que el motivo no sólo se ha retocado, sino que tomando como ejemplo otras piezas, se ha originado un motivo iconográfico híbrido, creado tomando elementos de unas y otras (Figura 7). Así pues, de la pieza Q1114 del British Museum (Bailey 1980,15) se ha tomado la crátera, la pantera y el tirso (Figura 7.1, A-C), que el alfarero ha sabido reposicionar bien en el soporte a decorar (disco) para permitir la incorporación de la parra, del tipo representado en la pieza Q766 de la misma colección (Bailey 1980, 15). Por otro lado, la contrastación cronológica de estos ejem- 


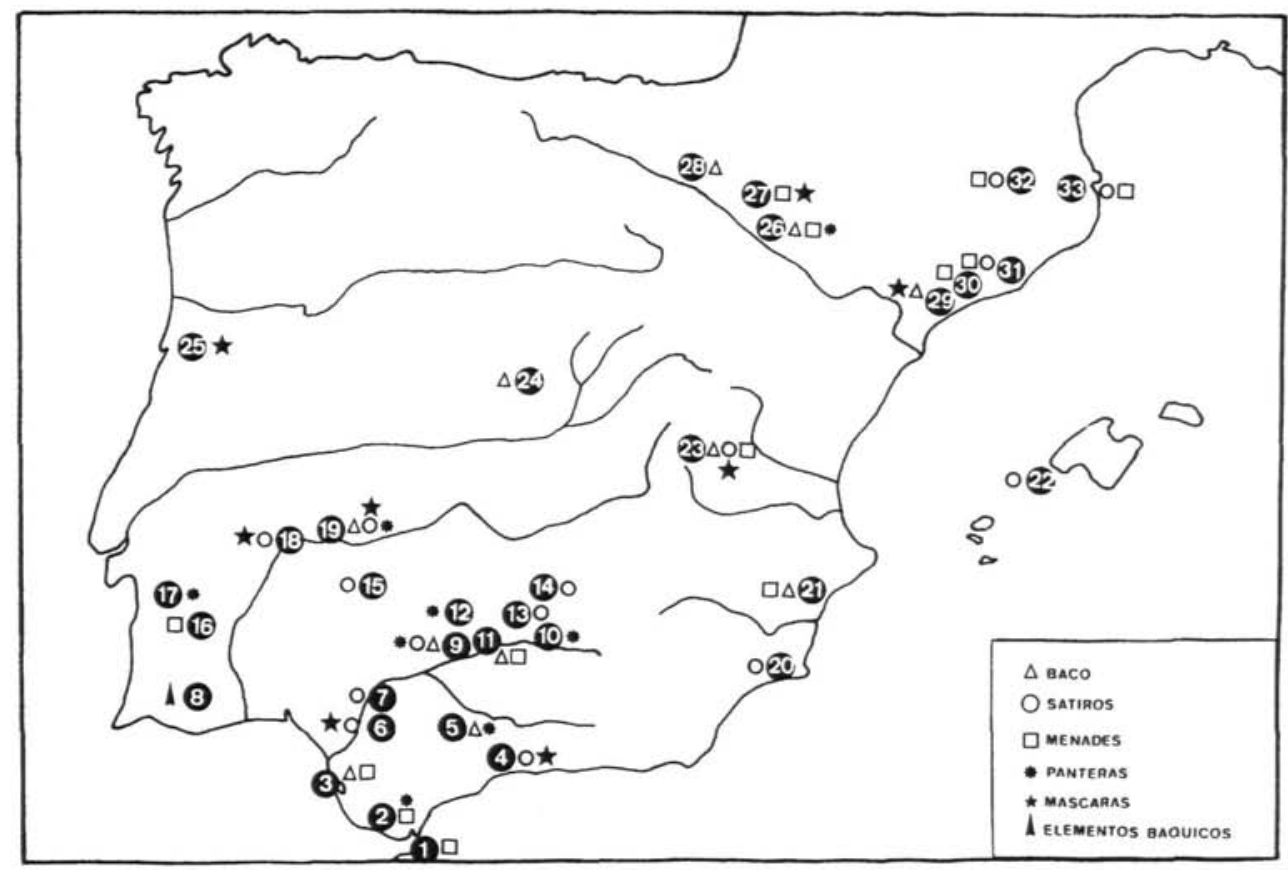

Figura 10. Distribución espacial de las lucernas con iconografía báquica en Hispania
01) Ceuta
02) Baelo Claudia (Bolonia, Cádiz)
03) Cádiz
04) Málaga
05) Osuna
06) Itálica (Santiponce)
07) Museo de Sevilla
08) Balsa
09 Córdoba
10) Tugi
11) Cerro Muriano (Córdoba)
12) Zhujeros (Córdoba)
13) Porcuna (Jaén)
14) Castellar de Santisteban
15) Villafranca de Barros
16) Peroguarda
17) Santiago de Caçem

18) Badajoz

19) Mérida

20) Cartagena

21) Tossal de Manises (Alicante)

22) Baleares

23) Segóbriga

24) Complutum (Alcalá de Henares)

25) Conimbriga (Codeixa la Vella)

26) Bilbilis (Calatayud)

27) Arcobrica

28) Calagurris (Calahorra)

29) Tarragona

30) Museo de Tarragona

31) Barcelona

32) Serra de Daró

33) Ampurias

34) Indeterminada 
plares parece ratificar esta hipótesis, pues el caso de la primera pieza citada se centra en un contexto cercano a momentos augusteos, pues se trata de una pieza temprana del tipo Bailey $\mathrm{A}^{14}$. Por su parte la pieza de Balsa se ajusta a la morfología de las Dressel 9, sin ser posible precisar la variante dada la mala calidad del aparato gráfico aportado. Nosotros nos inclinamos por tanto a considerar esta pieza de Balsa como un ejemplar de manufactura posiblemente hispana ${ }^{15}$.

\section{CONCLUSIONES}

Nuestro estudio ha estado encaminado, tal y como propusimos al inicio, a realizar una sistematización de todas las representaciones iconográficas relacionadas con un tema concreto, que en este caso ha sido el mundo dionisíaco. El índice de motivos que hemos realizado permite en primer lugar la rápida identificación del motivo, a través de la comparación con las representaciones en él recogidas. Asimismo, permite una correcta interpretación iconográfica, pues como hemos tenido ocasión de comprobar, la identificación de los temas no es la adecuada en todas las ocasiones, sobre todo en los casos de representaciones poco frecuentes o no recogidas en los principales catálogos de referencia.

Hemos podido comprobar cómo la interpretación de las escenas representadas en los discos de las lucernas se limita a la correcta identificación del motivo y a la búsqueda de paralelos ornamentales en lucernas, bien dentro del marco peninsular o fuera de él. Así pues, y tras prácticamente una centuria de trabajos al respecto, el corpus de motivos es amplísimo, y la correcta identificación de los mismos se produce en un $90 \%$ de los casos. Sin embargo, parece que con esto es suficiente, y así el frecuente apartado de "decoración" en este tipo trabajos no refleja más aspectos relacionados con el simbolismo ornamental. Tampoco es frecuente la búsqueda de los prototipos iconográficos, y más concretamente las fuentes de inspiración que han dado lugar a la aparición del motivo, normalmente procedentes de otros campos artísticos. Un tema, pues, interesantísimo, en el que deberemos centrarnos en los próximos anoos será el comenzar a establecer las relaciones existentes entre los figuli emisores de lucernas y los alfareros productores de vajillas finas de mesa. A este respecto ya contamos con algunos trabajos que comienzan a evidenciar las relaciones entre los punzones que decoraban las producciones en TSH y coetáneamente en lucernas romanas (Figura $7, \mathrm{n}^{\circ}{ }^{\circ} 3-4$ ). Este es pues un campo interesantísimo desde un punto de vista cronológico, pues la frecuencia de determinados motivos en lucernas y sincrónicamente en formas de Terra Sigillata nos va a permitir contrastar las cronologías de ambas producciones, llegando a precisar las de las lámparas, pues como sabemos las de las vajillas finas son más precisas y fluctuan menos.

${ }^{14}$ En cambio, no podemos precisar la cronología de la pieza Q766, dado su estado fragmentario.

$15 \mathrm{Al}$ no haber podido realizar un examen directo de la pieza no podemos ratificar esta propuesta. No obstante, la ausencia de paralelos por nosotros conocidos distribuidos por el resto del imperio parece apuntar en este sentido. 
Respecto a las zonas de procedencia de los materiales son algunos los problemas que se nos plantean como consecuencia de la realización de un estudio a nivel global como el nuestro. Así pues, las áreas de mayor concentración de piezas son indicativas de aquellas zonas en las que se han dado a conocer los repertorios. No resulta por tanto extraño que en puntos geográficos de notable importancia en el mapa de la Hispania romana falten datos sobre hallazgos de estas características. Para la Baetica contamos con una obra de conjunto que permite obtener una visión bastante indicativa del panorama general (Moreno 1991). Más o menos el mismo panorama lo tenemos en la zona catalana, con estudios sobre las grandes colecciones y yacimientos más significativos (Palol 1948-49;Bernal 1993b;Granados y Manera 1980; Arxé 1982 ${ }^{16}$ ), así como para la zona aragonesa (Amaré 1984a, 1988) y riojana (Amaré 1987a). Para el resto de la península el panorama es bastante más oscuro, pues si no faltan los estudios sobre la situación que aporta un yacimiento determinado (Remesal 1974;Rodríguez Neila 1977;Amante 1984;Morillo 1992;Fernández Ochoa y otros 1987;Abascal 1989), el panorama ofrecido por las colecciones, bien museísticas (Gil 1947-48;Fernández Chicarro 1952-53; Apraiz 1958;Manera 1978;Rodríguez Neila 1978-79;Fernández-Manera 1979;Modrezwska 1988; Olcina y otros 1991;Bernal 1993b; 1995) o particulares (López Rodríguez 1981;Amaré 1984b) es siempre parcial. Faltan pues estudios a nivel provincial, o en su defecto de las diversas circunscripciones geográficas o administrativas actuales.

Del mapa de distribución de los hallazgos de lucernas con representaciones de tipo báquico se observa un vacío en el cuadrante noroccidental de la península (Figura 10). Este hueco resulta, por el momento inexplicable, pero posiblemente debemos achacarlo a la carencia de repertorios publicados sobre la zona en cuestión ${ }^{17}$, pues trabajos recientes ponen de manifiesto la importancia de los mercados tanto atlánticos como de la fachada cantábrica, desde los primeros momentos de la romanización hasta las postrimerías del Bajo imperio, tal y como lo evidencian los hallazgos de vajillas finas de mesa de todo tipo y procedencia diseminadas por el Norte y noreste peninsular (Naveiro 1991, 27113;Fernández Ochoa y otros 1992, 105-149). Así pues, la inexistencia por el momento de una obra de conjunto, las piezas aisladas, publicadas en obras de carácter local o regional la mayor parte de las veces y normalmente no con carácter monográfico, no tienen siempre toda la difusión que sería de esperar. La poca densidad de hallazgos de lucernas en estas zonas, tanto figuradas como anicónicas, permite pensar en la existencia de medios alternativos de iluminación, tal y como se ha sugerido para otros casos, en proporcionalidad directa a la baja intensidad de la distribución de aceite bético en el norte.

Tras revisar los repertorios ornamentales de la TSH hemos podido comprobar que no existen frecuentes paralelismos en cuanto a motivos de tema báquico se refiere. Sólo

${ }^{16}$ Hacemos referencia exclusivamente a aquellas obras que hemos utilizado para la elaboración de este trabajo, sin la pretensión de ser exhaustivos en la recopilación bibliográfica. Así pues, cualquier ausencia literaria queda justificada de acuerdo a estas premisas.

17 Ya contamos con nuevos e interesantes datos inéditos sobre lucernas con representaciones báquicas en Astorga y León, según los datos facilitados por A.Morillo Cerdán. 
hemos podido localizar dos: el Tigerreiter y Baco con tirso. El primero de ellos ya fue identificado como tal por Sotomayor (1977, 73, n. ${ }^{\circ}$ 286-8, láms. 33-4). Sin embargo, Mayet considera este motivo un jinete, no atribuyéndole simbología báquica, a nuestro parecer evidente. Mayet asimila estas representaciones a los jinetes guerreros que aparecen en vasos de los talleres riojanos (1983-84, pl.XI, n. ${ }^{\circ}$ 66-7), pasando por alto la presencia del tirso en el caso cle las piezas de Andújar, y la clara identificación de la cabalgadura como un felino y no como un équido, tal y como la presencia de manchas en el pelaje del animal evidencian. Lo mismo sucede con otro motivo claramente báquico, como es el Diónisos con tirso (en el que se aprecian las cintas y las piñas) documentado en otra pieza de este mismo taller bético (Mayet 1983-84, pl.XXXVIII, n. ${ }^{\circ} 188$ ), sobre el cual la autora no efectúa ninguna identificación en su comentario iconográfico. No obstante, se trata de dos casos puntuales, no siendo pues habitual, como ya hemos comentado, la presencia de elementos vinculables al mundo báquico en el repertorio ornamental de la TSH. Tal afirmación puede deducirse del estudio de Méndez Revuelta, en cuyo "Indice del Corpus iconográfico" $(1976,7)$ observamos la ausencia del tema báquico en el apartado de divinidades. Asimismo, Elvira (1981) tampoco documenta la presencia de Baco entre las divinidades representadas en la TS de producción hispánica.

Otro punto que debe valorarse es la accidentalidad inherente a la distribución de las piezas decoradas, y por tanto la poca fiabilidad de las conclusiones que de su localización geográfica pudiésemos aventurar. En un mercado romano plagado de producciones cerámicas manufacturadas en serie prácticamente a niveles que podrían ser calificados de industriales, a la hora de evaluar el mapa de dispersión de las piezas debemos tener en cuenta siempre dos motivos:

- Se trata de productos elaborados en serie con una finalidad eminentemente utilitaria y no decorativa: son objetos destinados a proporcionar iluminación, sobre todo nocturna. Por tanto, la ornamentación constituye un elemento accesorio, y por ello las inferencias que hagamos de su distribución deben ser tomadas con cautela.

- El cliente no sabe exactamente qué es lo que está comprando: adquiere un producto de tipo funcional que a su vez consta de un motivo figurado que incrementa la calidad estética de la mercancía. Este fenómeno, muy bien documentado en el Mundo Antiguo, está muy bien testimoniado por las piezas elaboradas por la técnica del sobremolde $\mathrm{o}$-surmoulage-. Las piezas obtenidas por este sistema iban perdiendo progresivamente la nitidez de su decoración, hasta el punto de que en muchas de ellas el motivo llegaba prácticamente a perderse en su totalidad. Aunque el cliente sí identificaba el mensaje iconográfico inherente al producto que adquiría, no lo compraba para utilizarlo con un fin vinculado a la representación que aparecía en la pieza en cuestión ${ }^{18}$. Se trataba por tanto de un producto figurado, y por ello más apreciado por el consumidor.

${ }^{18}$ Este proceso es evidente en un elevado porcentaje de las lucernas emitidas por muchas de las officinae africanas, en las cuales se aprecia, ya desde el s. II d.C., una progresiva pérdida de calidad y de definición en los motivos de los discos. 
Tampoco podemos, por el momento, asociar la existencia de piezas con representaciones de tipo báquico a determinados ámbitos de la vida social. Carecemos de datos suficiente para vincular la presencia de piezas de simbología báquica (aunque esto es extensible a cualquier otro tipo de ornamentación) a la existencia en un determinado ambiente de mayor o menor arraigo de esta divinidad y a la documentación de rituales ligados a ella. Es más, no tenemos constancia de la aparición de lucernas con temas dionisíacos a otro tipo de materiales arqueológicos que sí testimonian fehacientemente cultos de tipo báquico. Lamentablemente no podemos constatar el hallazgo de lucernas en contextos arqueológicos asociados al culto báquico, tal y como sucede con las árulas dedicadas a Liber Pater halladas en los restos del templo de Montaña Frontera (Sagunto), o con los materiales epigráficos documentados en el templo dacio dedicado a Liber en Sarmizegetusa (García 1991a, 364-372).

Respecto a la secuencia cronológica de aparición de este tipo de piezas, observamos cómo se encuentran situadas en las dos primeras centurias de nuestra era. Este intervalo cronológico no supone a priori una época de auge o de mayor interés por los motivos relacionados con Baco. Simplemente responde al hecho de que es precisamente desde época augustea cuando la propia evolución morfológica de la lucerna romana va a permitir una mayor profusión de motivos. Es ahora cuando los discos de las lucernas se van haciendo progresivamente más planos y van aumentando sus dimensiones en detrimento de la orla, presentando ahora un marco muy propicio para albergar representaciones de todo tipo. No obstante, resulta sintomático el hecho de que las lucernas de disco van a perdurar al menos hasta finales del s. III d.C., si bien las recientes actuaciones arqueológicas indican que también están presentes en contextos más tardíos (Bernal 1994). Sin embargo, y tal y como hemos comentado, las representaciones báquicas en lucernas se circunscriben a los ss. I y II d. C., no siendo frecuentes en contextos bajoimperiales. Otro hecho digno de mención es la documentación de la mayor parte de nuestras piezas en contextos de s. I d.C., cuando tenemos constancia de que los elementos de Cultura Material referidos a esta divinidad se concentran fundamentalmente en la centuria siguiente (García 1991a) ${ }^{19}$.

La intencionalidad o al menos el conocimiento de la ornamentación la podemos rastrear desde los talleres itálicos de primera época. Dichas producciones centroitálicas, como en el caso de nuestra pieza n.$^{\circ} 53$, van a optar por un tipo de decoración determinada, en función de unos criterios precisos, pues es ahora cuando se está gestando el repertorio iconográfico para este tipo de piezas cerámicas. Es por tanto en el ámbito itálico ${ }^{20}$ de finales s. I a.C. donde debemos rastrear esas preferencias por unos u otros punzones, y no a nivel provincial, donde el panorama se enturbia mucho más. La extremada dificul-

${ }^{19}$ Este hecho lo tenemos ejemplificado en la reciente revisión de los documentos epigráficos de Liber en Hispania, cuya datación se centra en el s. II d.C.(Hoyo 1992,87).

${ }^{20}$ Conscientes de que los origenes de las primeras producciones de volutas debemos buscarlo posiblemente en el mundo Próximo oriental, es indiscutible que la península itálica se convierte desde muy pronto en el verdadero catalizador del proceso de producción de estos primeros tipos de lucernas que ya podemos definir como plenamente romanas. 
tad de distinguir, por el momento, entre los productos de importación y las copias provinciales a imitación de los productos itálicos resulta evidente, por ejemplo en el caso las lucernas de disco más canónicas. Por tanto no podemos hoy por hoy constatar si los alfareros hispanos optaban por un tipo de decoración determinada en el amplio repertorio iconográfico existente o bien còpiaban los motivos * a granel - sin intencionalidad alguna. Debemos esperar en primer lugar a una correcta caracterización de las producciones hispanas de imitación itálica antes de aventurar conclusiones válidas a nivel general ${ }^{21}$.

De las 88 piezas que hemos traído a colación, 49 son altoimperiales, 32 del s. I d.C., 4 entre el s. I y II d.C. (n . ${ }^{\circ} 21,37,54$ y 55), 1 plenamente del s. II d.C. (n. $\left.{ }^{\circ} 26\right)$ y 2 entre el s. II-III d.C. (n. 02 y 71$)$.

No teniendo en cuenta los ejemplares que datamos genéricamente en época altoimperial, pues su estado fragmentario no nos permite una clasificación más precisa, el resto del material (37 lucernas) nos permite ubicar el $80 \%$ aproximadamente de las mismas en el s. I d.C., correspondiendo su totalidad a formas relacionables con la familia de las lámparas de volutas. Es en esta época en la que vamos a encontrar en Hispania un mayor volumen de productos con representaciones dionisíacas, la mayor parte de ellas procedentes de talleres itálicos, pues aún en este momento los talleres norteafricanos no han comenzado a invadir el mercado mediterráneo con sus productos.

Respecto a la cronología determinada de cada motivo en sí, remitimos al correspondiente apartado en el análisis iconográfico.

Así pues, cumplimos uno de nuestros objetivos, el dotar a una serie de motivos de una cronología relativa que permita al que cuente con una pieza en estado fragmentario que presente una iconografía afín a las propuestas datar su pieza por cronología relativa en este intervalo cronológico.

\section{BIBLIOGRAFÍA}

ABASCAL, J. M., 1989: -Lucernas romanas de Segóbriga- en M.Almagro, A.Lorrio, Segobriga III.La muralla Norte y la puerta principal, Cuenca, 299-341.

Alarcao, J.; Delgado, M.; Mayet, F.; Moutinho, A., y Da Ponte, S., 1976: Fouilles de Conimbriga VI, Céramiques diverses et verres, París.

${ }^{21}$ En el caso de las formas de producción hispánica caracterizadas por presentar algún rasgo formal definitorio, como por ejemplo las lucernas mineras onubenses, el problema se disipa. Sin embargo, cuando la copia de la forma es integra y el alfarero no aporta nada innovador, el resultado inmediato es la mezcla de ambas producciones. Es este campo, la caracterización de los productos de imitación que aún hoy se confunden con los importados, el que más sorpresas nos deparará en los próximos años, tal y como ya comenzamos a percihir (Bernal 1993a). 
Álvarez OSSORIO, F., 1942: "Lucernas o lámparas antiguas de barro cocido del Museo Arqueológico Nacional", Archivo Español de Arqueología XV, 271-287.

Amante SánCheZ, M., 1984: "Las lucernas de Begastri (estudio previo)", Antigüedad y Cristianismo, 1, Murcia 1984, 85-91.

- 1988: "Representaciones iconográficass en lucernas romanas de la región de Murcia", Antigüedad y Cristianismo, V, 213-254.

Amaré TAFAlla, M. T., 1984a: Lucernas romanas de Bilbilis, Zaragoza.

- 1984b: "Lucernas romanas de la colección de don J.Cabré Aguiló", Homenaje a J.Cabré, Zaragoza, 207-215.

- 1987a: Lucernas romanas de La Rioja, Logroño.

- 1987b: :Lucernas romanas del Convento Jurídico caesaraugustano: provincias de Guadalajara y Madrid-, Wad-al-Hayara 14, 9-34.

- 1988: Lucernas romanas en Aragón, Zaragoza.

APRAIZ, R. DE, 1958: Lucernas romanas en el Museo Numantino, Madrid.

ARXE I GÁLVEZ, J., 1982: Les llánties tardorepublicanes d'Empuries, Barcelona.

BÁdenAs, P., y Olmos, R., 1988: "La nomenclatura de los vasos griegos en castellano. Propuestas de uso y normalización" Archivo Español de Arqueologia 61, 61-80.

BAILEY, D. .M., 1980: A Catalogue of the lamps in the British Museum, II: Roman Lamps made in Italy, Londres.

- 1988: A Catalogue of the Lamps in the British Museum, III: Roman Provincial Lamps, Londres.

BELCHIOR, C., 1969: Lucernas romanas de Conimbriga, Coimbra.

BERGes, G., 1989: Les lampes de Montans (Tarn). Une production des I et II s. ap. J.C. Documents d'Archéologie Française 21, París.

Bernal CaSasola, D., 1993a: "Figuli hispani: testimonios materiales de manufactura peninsular de lucernas en época romana", Opus, IX-X, 147-160.

- 1993b: “Lucernae tarraconenses: las lucernas romanas del Museu Nacional Arqueològic y del Museu i Necropolis Paleocristians del Tarragona ", Butlletí Arqueològic, Tarragona, época V, 15, pp. 59-298.

- 1994: :Economía lychnológica hispana: valoración actual del proceso de manufactura peninsular de lucernas en época romana y su inserción en el contexto mediterráneom, I Congresso de Arqueología Peninsular (Oporto 1993).

- 1995: Las lucernas romanas del Museo Municipal de Ceuta, Cuadernos del Rebellín 12, Ceuta. 
BONNET, J., 1989: Lampes céramiques signées, Documents d'Archéologie Française 13, París.

Cumont, F., 1966: Recherches sur le symbolisme funéraire des romains, París.

Deneauve, J., 1969: Lampes de Cartaghe, París.

Domergue, C., 1966: " Un envoi de lampes du potier Caius Clodius", Melanges de la Casa de Velazquez 2, París, 5-40.

DRESSEL, H., 1899: “Lucernarum formae», C.I.L. XV, II, 1, lámina III.

Elvira BARBA, M. A., 1981: "Los dioses romanos en la terra sigillata hispánica", en VV.AA., La religión romana en Hispania, Madrid.

FERNÁNDEZ CHICARRO, C., 1952-53: "La colección de lucernas antiguas del Museo Arqueológico de Sevilla", Memorias de los Museos Arqueológicos Provinciales XIII-XIV, 61-124.

FERnÁndez Galiano, D., 1984: Complutum II: mosaicos, Excavaciones Arqueológicas en España 138.

FERnÁNDEZ, J. H., y MANERA, E., 1979: “Lucernas romanas del Museo Arqueológico de Ibiza", Trabajos del Museo Arqueológico de Ibiza I.

Fernández OCHOA, C.; Seldas, I., y CABALlero, A., 1987: "Lucernas romanas de la Bienvenida (Ciudad Real)", Oretum III, 263-290.

Fernández OCHOA, C.; García Díaz, P., y UsCatescu, A., 1992: "Gijón en el periodo tardoantiguo: cerámicas importadas de las excavaciones de Cimadevilla", Archivo Español de Arqueología 65, 105-49.

Ferreira de AlmeIdA, J. A.. 1951: "Três lucernas do Museu de Santiago de Caçem", O Arqueologo Portugues I, 125-130.

- 1953: -Introdução ao estudo das lucernas romanas em Portugal», O Arqueologo Portugues, II, 5-208.

García Y Bellido, A., 1970: "Los hallazgos cerámicos del área del templo de Córdoba" Anejos de Archivo Español de Arqueología 5.

García SAnZ, O., 1991a: Baco en Hispania.Economía y religión a través de las fuentes epigráficas, arqueológicas y literarias, Tesis Doctoral, Universidad Complutense de Madrid.

Gran AYMERICH, J., 1991: Malaga phénicienne et punique, París.

GIL FARRÉS, O., 1947-48: -Lucernas romanas decoradas del Museo Emeritense•, Ampurias IX-X, 97-115.

Granados, J. O., y MAnERA, E., 1980: -Lucernas romanas de la colonia Barcino, I: Lucernas procedentes de la Plaza del Rey y Casa Padellás", Quaderns d'Arqueologia $i$ Historia de la Ciutat, XVIII, 51-68. 
GRIÑó, B., 1985: «La influencia de la música griega y mediterránea en las culturas de la Península Ibérica", en VV.AA.,Ceràmiques gregues $i$ helenístiques a la Península Ibèrica, Barcelona, 151-167.

Gurt Esparraguera, J. M., 1985: Clunia III, Excavaciones Arqueológicas en España.

Hoyo Calleja, J. del, 1992: "Revisión de los estudios de Liber Pater en la epigrafía hispana", Mélanges de la Casa de Velazquez XXVIII/1, 65-92.

LeITE DE VASCONCELO, J., 1913: Nuevas divinidades de Lusitania, Lisboa.

LIMC, 1986a: Lexicon Iconographicum Mythologiae Classicae, III,1, Zürich-München 1986, s.v. Dionysos.

- 1986b: Lexicon Iconographicum Mythologiae Classicae, III,1, Zürich-München 1986, s.v. Bacchus.

LÓPEZ RODRíGuEZ, J. R., 1981: :La colección de lucernas de la casa de la Condesa de Lebrija ( Sevilla ), Boletin del Seminario de Estudios de Arte y Arqueología XLVII, 95-140.

LuZÓN, J. M., 1978: “Die neuattischen Rundaren von Italica”, Madrider Mitteilungen 19, pp. $272-284$.

MANERA, E., 1978: "Lucernas romanas de Pollentia en el Museo de Mallorca", Trabajos del Museo de Mallorca 26, 218-237.

Mansuel.i, G. A., 1958: Galleria degli Uffici: le sculture, Roma.

MAYET, F., 1983-84: Les céramiques sigillées hispaniques. Contribution à l'bistoire économique de la Péninsule Ibérique sous l'Empire romain I, II, París.

MÉLIDA, J. R., 1925: Catálogo Monumental de la Provincia de Badajoz, I, Madrid.

MÉNDEZ REVUELTA, C., 1976: Materiales para el estudio de la figura humana en el temario decorativo de la terra sigillata bispánica, Studia Archaeologica 41, Valladolid-Santiago.

MODREZWSKA, I., 1988: "Lucernas tardoantiguas en la colección del M.A.N.", Boletín del Museo Arqueológico Nacional VI 1-2, 25-58.

MORENO JiMÉNEZ, F., 1991: Lucernas romanas en la Bética, Tesis Doctoral, Universidad Complutense, Madrid, tomos I-III.

MORILlo CERDÁN, A., 1992: Cerámica romana de Herrera de Pisuerga (Palencia, España): las lucernas, Edic. Univ. Intern. Sek, Santiago de Chile.

Moutinho AlarCaO, A., 1976: "As lucernas romanas do Paço Ducal de Vila Viçosa",_Conimbriga, XV.

NAVEIRO, J., 1991: El Comercio antiguo en el N.W. peninsular, La Coruña.

NOLla, J. M., y CASAS, J., 1984: Carta arqueològica de les comarques de Girona, Gerona. 
Nunes RiBeIro, F., 1960: "Lucernas romanas de Peroguarda", Arquivo de Beja XVI, Beja, 79-102.

Olcina, C.; Reginard, H., y SÁnChez, M. J., 1991: Tossal de Manises (Albufereta,Alicante).Fondos Antiguos: lucernas y sigillatas, Alicante.

OSWALD, F., 1936-37: Index of Figure-types on Terra sigillata ("Samian Ware"), Liverpool.

PAlAnQues SALmerón, M. L., 1992: Las lucernas de Pollentia. Monografias de la W. Bryant Foundation 4, Palma de Mallorca.

PAlOL, P. de, 1948-49: “La colección de lucernas romanas de cerámica procedentes de Ampurias en el Museo Arqueológico de Gerona", Memorias de los Museos Arqueológicos Provinciales IX-X, 233-265.

REINACH, S., 1930: Répertoire de la statuaire grecque et romaine, París.

Rfmesal, J., 1974: "Les lampes à huile de Belo au Musée Archéologique National de Madrid",Melanges de la Casa de Velazquez X, 561-573.

Rodríguez NeILA, J. F., 1977: "Serie de lucernas de Osuna”, Habis 8, 385-397.

- 1978-79: "Lucernas romanas expuestas al público en el Museo Arqueológico de Córdoba", Corduba 7, 1-7.

RODríguez Oliva, P., 1978: "Dos hermae malacitanos", Jábega 23, 65-72.

SAPELLI, M., 1979: Lucerne fittili delle civique raccolte archeologique, Rassegna di studi del Museo Archeologico e del Civico Gabinetto numismatico di Milano, sup. II, Milán.

SERRA VILARÓ, J., 1935: "Excavaciones en la necropolis romano-cristiana de Tarragona", Memorias de la Junta Superior de Excavaciones y Antigüedades, 133, 1-85, lam. I-1.

SOTOMAYOr Muro, M., 1977: Marcas y estilos en la sigillata decorada de Andújar, Jaén.

Tram Tam Tinh, 1964: Le culte d'Isis à Pompei, París. 